\title{
Diversity and evolution of nitric oxide reduction
}

3 Ranjani Murali ${ }^{1, a^{*}}$, Laura A. Pace ${ }^{2}$, Robert A. Sanford ${ }^{3}$, Lewis M. Ward ${ }^{4}$, Mackenzie

4 Lynes $^{5}$, Roland Hatzenpichler ${ }^{5,6}$, Usha F. Lingappa ${ }^{7}$, Woodward W. Fischer ${ }^{8}$, Robert B.

5 Gennis $^{9}$, James Hemp ${ }^{2,8, a^{*}}$

6

$7 \quad{ }^{1}$ Division of Biology and Biological Engineering, California Institute of Technology,

8 Pasedena, CA, USA

$9 \quad{ }^{2}$ Metrodora Institute, Salt Lake City, UT, USA

$10{ }^{3}$ Department of Geology, University of Illinois at Urbana-Champaign, Urbana, IL, USA

$11{ }^{4}$ Smith College, Northampton, MA, USA

$12{ }^{5}$ Department of Chemistry and Biochemistry, Thermal Biology Institute, and Center for

13 Biofilm Enginering, Montana State University, MT, USA

$14{ }^{6}$ Department of Microbiology and Cell Biology, Montana State University, MT, USA

$15{ }^{7}$ Department of Plant and Microbial Biology, University of California, Berkeley, CA,

$16 \quad$ USA

$17{ }^{8}$ Division of Geological and Planetary Sciences, California Institute of Technology,

18 Pasadena, USA

$19{ }^{9}$ Department of Biochemistry, University of Illinois, Urbana-Champaign, Urbana, USA

20 a James Hemp and Ranjani Murali contributed equally to the work in this manuscript.

$21{ }^{*}$ Corresponding authors: E-mail: james.hemp@metrodora.org, m.ranjani@gmail.com 
25 Nitrogen is an essential element for life, with the availability of fixed nitrogen

26 limiting productivity in many ecosystems. The return of oxidized nitrogen species to

27 the atmospheric $\mathrm{N}_{2}$ pool is predominately catalyzed by microbial denitrification

$28\left(\mathrm{NO}_{3}{ }^{-} \rightarrow \mathrm{NO}_{2}{ }^{-} \rightarrow \mathrm{NO} \rightarrow \mathrm{N}_{2} \mathrm{O} \rightarrow \mathrm{N}_{2}\right)^{1}$. Incomplete denitrification can produce $\mathrm{N}_{2} \mathrm{O}$ as

29 a terminal product, leading to an increase in atmospheric $\mathbf{N}_{2} \mathrm{O}$, a potent greenhouse

30 and ozone-depleting gas ${ }^{2}$. The production of $\mathrm{N}_{2} \mathrm{O}$ is catalyzed by nitric oxide

31 reductase (NOR) members of the heme-copper oxidoreductase (HCO) superfamily ${ }^{3}$.

32 Here we use phylogenomics to identify a number of previously uncharacterized

33 HCO families and propose that many of them (eNOR, sNOR, gNOR, and nNOR)

34 perform nitric oxide reduction. These families have novel active-site structures and

35 several have conserved proton channels, suggesting that they might be able to

36 couple nitric oxide reduction to energy conservation. We isolated and biochemically

37 characterized a member of the eNOR family from Rhodothermus marinus, verifying

38 that it performs nitric oxide reduction both in vitro and in vivo. These newly

39 identified NORs exhibit broad phylogenetic and environmental distributions,

40 expanding the diversity of microbes that can perform denitrification. Phylogenetic

41 analyses of the HCO superfamily demonstrate that nitric oxide reductases evolved

42 multiple times independently from oxygen reductases, suggesting that complete

43 denitrification evolved after aerobic respiration.

44 The HCO superfamily is extremely diverse, with members playing crucial roles in both

45 aerobic (oxygen reductases) and anaerobic (nitric oxide reductases) respiration. The

46 superfamily currently consists of at least three oxygen reductase families (A, B and C)

47 and three NOR families (cNOR, qNOR, and $\left.\mathrm{qCu}_{\mathrm{A}} \mathrm{NOR}\right)^{4}$. The oxygen reductases 
48 catalyze the reduction of $\mathrm{O}_{2}$ to water $\left(\mathrm{O}_{2}+4 \mathrm{e}_{\text {out }}{ }^{-}+4 \mathrm{H}_{\mathrm{in}}{ }^{+}+\mathrm{nH}_{\mathrm{in}}{ }^{+} \rightarrow 2 \mathrm{H}_{2} \mathrm{O}+\mathrm{nH}_{\text {out }}{ }^{+}\right)$and

49 share a conserved reaction mechanism ${ }^{5,6}$, where three of the electrons required to reduce

$50 \mathrm{O}_{2}$ are provided by the active-site metals, heme-Fe and $\mathrm{Cu}_{\mathrm{B}}$, while the fourth electron is

51 derived from a redox-active cross-linked tyrosine cofactor $^{7}$ (Figure 1). The free energy

52 of the reaction is converted to a transmembrane proton electrochemical gradient by two

53 different mechanisms, charge separation across the membrane and proton pumping ${ }^{8-10}$.

54 Both the chemical and pumped protons are taken up from the electrochemically negative

55 side of the membrane (bacterial cytoplasm) via conserved proton-conducting channels

56 that are comprised of conserved polar residues and internal water molecules. The

57 different oxygen reductase families exhibit differential proton pumping stochiometries

58 ( $n=4$ for the A-family, and $n=2$ for the $B$ and C-families ${ }^{8-10}$, depending on the details of

59 their conserved proton channels. The oxygen reductases also vary in their secondary

60 subunits that function as redox relays from electron donors to the active-site, with the A

61 and $\mathrm{B}$-families utilizing a $\mathrm{Cu}_{\mathrm{A}}$-containing subunit ${ }^{11-13}$ and the $\mathrm{C}$-family containing one or

62 more cytochrome $c$ subunits $^{14}$ (Figure 1).

64 Nitric oxide reductases (NORs) catalyze the reduction of nitric oxide to nitrous oxide

$65\left(2 \mathrm{NO}+2 \mathrm{H}_{\text {out }}{ }^{+}+2 \mathrm{e}_{\text {out }}^{-}+\mathrm{nH}_{\mathrm{in}}{ }^{+} \rightarrow \mathrm{N}_{2} \mathrm{O}+\mathrm{H}_{2} \mathrm{O}+\mathrm{nH}_{\text {in }}{ }^{+}\right)$. Nitric oxide reduction is only a 2-

66 electron reaction, so it does not require the cross-linked tyrosine cofactor for catalysis.

67 There are currently three known HCO NORs, the cNOR, qNOR, and $\mathrm{qCu}_{\mathrm{A}} \mathrm{NOR}$. The

68 cNOR and qNOR families have a four amino acid coordinated $\mathrm{Fe}_{\mathrm{B}}$ ion in their active-

69 sites, in contrast to the three amino acid coordinated $\mathrm{Cu}_{\mathrm{B}}$ found in oxygen reductases ${ }^{15,16}$.

70 The cNOR and qNOR families are closely related to the C-family oxygen reductases and 
71 likely evolved from this oxygen reductase family. In accordance with this relationship,

72 the cNORs have a secondary cytochrome $c$-containing subunit, while in the qNORs the

73 two subunits corresponding to those in the cNORs have been fused to a single subunit

74 that lacks the heme $c$ binding. Although, the qNOR from $N$. meningitidis ${ }^{16}$ is proposed to

75 take up protons from the cytoplasm for NO reduction, neither the cNOR nor qNOR have

76 conserved residues that could form a proton channel from the cytoplasm, therefore it is

77 unlikely that they conserve energy via either charge separation or proton pumping $(\mathrm{n}=0$

78 for the cNOR and $\mathrm{qNOR}$ families). Phylogenomic analysis shows that the $\mathrm{qCu}_{\mathrm{A}} \mathrm{NOR}$

79 from Bacillus azotoformans ${ }^{17,18}$ is unrelated to the qNOR family, and has been

80 reclassified here as the bNOR family. The bNOR active-site structure is fundamentally

81 different than those from the cNOR and qNOR families (Figure 1). It also contains a

82 conserved proton channel that is very similar to that found in the B-family oxygen

83 reductases (Figure 1), and has been shown to be electrogenic ${ }^{18}$. This has important

84 consequences for the efficiency of energy conservation associated with denitrification ${ }^{19}$.

85

\section{Novel heme-copper oxygen reductase homologs}

87 Phylogenomic analyses of genomic and metagenomic data have identified at least six

88 new families belonging to the HCO superfamily (Figure 2). All of these families are

89 missing the active-site tyrosine, suggesting that they do not catalyze $\mathrm{O}_{2}$ reduction.

90 Furthermore, their active-sites exhibit structural features never seen before within the

91 superfamily (Figure 1). One of these families is closely related to qNOR and has been

92 proposed to be a nitric oxide dismutase contributing to $\mathrm{O}_{2}$ production in 'Candidatus

93 Methylomirabilis oxyfera ${ }^{20}$. Another family is closely related to cNOR and might be a 
94 sulfide and acetylene insensitive nitrous oxide reductase ${ }^{21,22}$. The remaining four families

95 (eNOR, sNOR, nNOR and gNOR) are closely related to the B-family of oxygen

96 reductases (Figure 2) and encode for homologs of the $\mathrm{Cu}_{\mathrm{A}-\text { containing secondary }}$

97 subunits, consistent with this evolutionary relationship (Figure 1, Table S1). Based on

98 modeled active-site structures and genomic context we propose that these four families

99 perform nitric oxide reduction (Figure 1).

\section{Biochemical characterization of eNOR}

102 To validate these predictions we isolated and biochemically characterized a member of

103 the eNOR family from Rhodothermus marinus DSM 4252, a thermophilic member of the

104 Bacteroidetes phylum. Rhodothermus marinus was originally classified as a strict

105 aerobe $^{23}$, but its genome encodes a periplasmic nitrate reductase (NapA), two nitrite

106 reductases (NirS and NirK), and a nitrous oxide reductase (NosZ), suggesting that it may

107 also be capable of denitrification (Extended Data Figure 1). Denitrification was not

108 observed under strictly anaerobic conditions, however under microoxic conditions

109 isotopically labeled ${ }^{15} \mathrm{NO}_{3}^{-}$was converted to ${ }^{30} \mathrm{~N}_{2}$ (Extended Data Figure 2)

110 demonstrating that $R$. marinus DSM 4252 is capable of complete aerobic denitrification

$111\left(\mathrm{NO}_{3}{ }^{-} \rightarrow \mathrm{N}_{2}\right)$. Blockage of the nitrous oxide reductase with acetylene led to the

112 accumulation of $\mathrm{N}_{2} \mathrm{O}$ (Figure 3), suggesting that a nitric oxide reductase was also present

113 in $R$. marinus DSM 4252. No known NORs (cNOR, qNOR, qCuANOR) were found in

114 the genome. However, R. marinus DSM 4252 does encode for a member of the eNOR

115 family (Extended Data Figure 1). 
117 Isolation and biochemical characterization of the $R$. marinus DSM 4252 eNOR protein

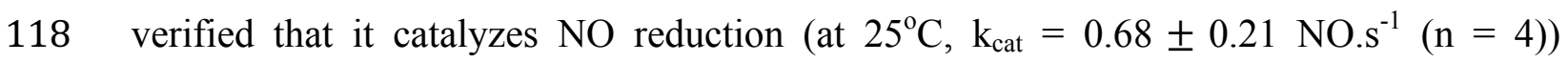

119 (Figure 3). eNOR was unable to catalyze $\mathrm{O}_{2}$ reduction using various electron donors

120 (Extended Data Figure 3), clearly showing that it functions solely as a nitric oxide

121 reductase. UV-Vis spectroscopy and heme characterization via mass spectrometry

122 demonstrated that the $R$. marinus DSM 4252 eNOR contains a novel modified heme $a$

123 that is used in both heme sites (Figure 3 and Extended Data Figures 3 and 4). A

124 member of the eNOR family was previously isolated from the aerobic denitrifier

125 Magnetospirillum magnetotacticum MS-1 ${ }^{16,17}$, however its function was never

126 determined. The UV-Vis spectra of the M. magnetotacticum $\mathrm{eNOR}^{17}$ is identical to the $R$.

127 marinus eNOR, suggesting that the modified heme $a$ is a general feature of the family.

128 Mass spectrum analysis of the hemes extracted from eNOR suggest that this heme is $\mathrm{A}_{\mathrm{s}}$, a

129 previously isolated heme $a$ with a hydroxyethylgeranylgeranyl side chain first identified

130 in the B-family oxygen reductase from Sulfolobus acidocaldarius ${ }^{24}$. Many eNOR operons

131 contain a CtaA homolog, an $\mathrm{O}_{2}$-dependent enzyme that converts heme $o$ to heme $a^{25}$.

132 This is consistent with the observation that eNOR requires microoxic conditions for

133 expression and suggests that aerobic denitrification might be common in nature.

135 Active-site features of novel NORs

136 In addition to the experimental evidence that both eNOR and bNOR enzymes are NO

137 reductases, there is good evidence that the other newly identified families also perform

138 nitric oxide reduction. The sNOR family has the same active-site structure as the bNOR

139 family, strongly suggesting that it also performs nitric oxide reduction. However, the 
140 sNOR and bNOR families are not closely related, providing an example of convergent

141 evolution of active-site structures within the HCO superfamily (Figures 1 and 2).

142 Another example of convergent evolution is the nNOR family. It has the same conserved

143 active-site residues as the cNOR and qNOR families (Figure 1), but is very distantly

144 related to them (nNOR is related to the B-family, while cNOR and qNOR are related to

145 the C-family). Interestingly, the low-spin heme in nNOR is ligated by a histidine and

146 methionine, which likely raises its redox potential by $\sim 150 \mathrm{mV}^{26}$. This is similar to a

147 modification found in some eNORs, where the low spin heme is ligated by histidine and

148 lysine. The gNOR is the first example of a HCO family that has replaced one of the

149 active-site histidines, residues completely conserved in all other families. A bioinorganic

150 mimic of the gNOR active-site exhibited nitric oxide reduction capability ${ }^{27}$, suggesting

151 that it is likely a functional NOR in vivo. The gNOR has a secondary subunit with a

152 cupredoxin fold that is missing the residues required to bind $\mathrm{Cu}_{\mathrm{A}}$, similar to the quinol

153 oxygen reductase from E. coli. Conserved residues that could bind quinol have been

154 identified in gNOR, suggesting that it is a quinol nitric oxide reductase similar to qNOR.

156 The biochemically characterized (eNOR and bNOR) and proposed (sNOR and gNOR)

157 HCO NORs have active-sites that differ significantly from those utilized by cNOR and

158 qNOR (Figure 1). This demonstrates that while oxygen reduction chemistry is

159 constrained to require a redox active tyrosine cofactor, multiple HCO active-site

160 structures are compatible with nitric oxide reduction chemistry. Interestingly, in the

161 currently characterized $\mathrm{HCOs} \mathrm{Cu}_{\mathrm{B}}$ is utilized for $\mathrm{O}_{2}$ reduction chemistry and $\mathrm{Fe}_{\mathrm{B}}$ for $\mathrm{NO}$

162 reduction chemistry. If this pattern is verified for the other predicted NOR families it 
163 would suggest that the chemistry performed by HCOs is partially determined by the

164 electronic properties of the active-site metal.

\section{Bioenergetics of novel denitrification pathways}

167 Although both denitrification and aerobic respiration are highly exergonic processes,

168 most of the enzymes in the denitrification pathway are not coupled to energy

169 conservation, making denitrification significantly less efficient than aerobic respiration ${ }^{28}$.

170 In the HCO oxygen reductases conserved proton channels deliver protons from the

171 cytoplasm to the active-site for chemistry. These same channels are used to pump protons

172 to the periplasmic side. The cNORs and qNORs do not have conserved proton channels

173 from the cytoplasm ${ }^{15,29}$, making them incapable of conserving energy. The eNOR has

174 conserved residues that closely resemble those found in the proton-conducting K-channel

175 within the B-family of oxygen reductase ${ }^{30}$ (Supplementary Table 1, Extended Data

176 Figure 5). The sNOR family also has conserved residues in the K-channel region,

177 however they are different than those found in the eNOR and bNOR families.

178 Interestingly, the nNOR family, which has the same active site as cNOR and qNOR, also

179 has a conserved proton channel (Supplementary Table 1, Extended Data Figure 5),

180 suggesting that the lack of a proton channel in the cNOR and qNOR may not be due to

181 energy constraints ${ }^{31}$. The conserved proton channels in the eNOR, bNOR, sNOR, and

182 nNOR families would allow them to conserve energy via charge separation, and

183 potentially by proton pumping. Characterization of these new NOR families will be

184 critical for a full understanding of the mechanism of proton pumping in the $\mathrm{HCO}$

185 superfamily, one of the most important unanswered question in bioenergetics. 


\section{Distribution and environmental relevance of NORs}

187 The new HCO NOR families have broad phylogenetic and environmental distributions

188 (Table 1, Supplementary Tables 2, 3). The eNOR, sNOR, gNOR, and nNOR families

189 are found in both Bacteria and Archaea. To date, the bNOR family has been found only

190 in the Bacillales order of Firmicutes (Supplementary Table 2). Phylogenetic analysis of

191 metagenomic data shows that the majority of eNOR, sNOR, gNOR, and nNOR enzymes

192 are from uncharacterized organisms, suggesting that many more organisms are capable of

193 nitric oxide reduction than previously suspected. Furthermore, the new HCO NOR

194 families are found in a wide variety of environments (Table 1, Supplementary Table 2).

195 The sNOR are found in the majority of ammonia oxidizing bacteria sequenced to date

196 and likely play a role in this process. The gNORs are predominantly found in sulfidic

197 environments and may be an adaptation that allows for denitrification in the presence of

198 sulfide, which inhibits other NOR families. The eNOR family is very common in nature,

199 having a broad distribution similar to the cNOR and qNOR families. The eNOR family

200 appears to play key roles in a number of important microbiological processes. They are

201 found in many strains of Candidatus Accumulibacter phosphatis, a microbe utilized for

202 phosphate accumulation in wastewater treatment plants during enhanced biological

203 phosphorus removal. The eNOR is highly expressed in transcriptomic datasets from

204 these facilities, demonstrating that Accumulibacter phosphatis is capable of complete

205 denitrification in $s^{3} u^{32}$. eNOR has also been found in microbes capable of performing 206 autotrophic nitrate reduction coupled to $\mathrm{Fe}(\mathrm{II})$ oxidation (NRFO). Gallionellaceae KS

207 and related strains express an eNOR under denitrifying conditions, suggesting that an 208 individual organism is capable of complete $\mathrm{NRFO}^{33}$. eNOR is also commonly found in 
209 hypersaline environments (Supplementary Table 2) where is might play a role in the

210 adaptation of denitrification to high salt conditions.

211

212 Many organisms encode NORs from multiple families (e.g., Ca. Methylomirabilis

213 oxyfera has a qNOR, sNOR and gNOR, and Bacillus azotoformans has a qNOR, sNOR,

214 and bNOR). This suggests that selection for different enzymatic properties (NO affinity,

215 enzyme kinetics, energy conservation, or sensitivity to inhibitors) or the concentration of

$216 \mathrm{O}_{2}$ may be important factors in determining their distribution, similar to what is observed

217 for the HCO oxygen reductase families ${ }^{8}$. Analysis of the presence of denitrification genes

218 (nitrite reductases, nitric oxide reductases, and nitrous oxide reductases) within

219 sequenced genomes indicates that many more organisms are capable of complete

220 denitrification than previously realized. Our current understanding of the diversity of

221 organisms capable of performing denitrification is far from complete.

222

223 Our evolutionary analysis shows that nitric oxide reductases have evolved many times

224 independently from oxygen reductases (Figure 2). The current data show that NORs

225 have originated from both the B and C-families of oxygen reductases, enzymes that are

226 adapted to low $\mathrm{O}_{2}$ environments. These oxygen reductases can reduce $\mathrm{NO}$ at high

227 concentrations in vitro ${ }^{34}$ so it is not surprising that small evolutionary modifications

228 would lead to enzymes capable of NO reduction at the lower NO concentrations

229 produced during denitrification. The fact that NO reductases are derived from oxygen

230 reductases strongly suggests that complete denitrification evolved after aerobic 
231 respiration. This places important constraints on the nitrogen cycle before the rise of

232 oxygen.

\section{Competing Interests}

235 The authors declare no competing interests.

\section{Acknowledgment}

237 We would like to thank NIH for funding this research (Grant \# , Principle Investigator:

238 Dr. Robert Gennis). We thank Sylvia Choi for providing pure $b a_{3}$ oxygen reductase from

239 Thermus thermophilus to use as a control for oxygen reductase assays and for heme

240 extraction, Lici Schurig-Briccio for guidance in performing nitric oxide reductase assays

241 with the Clark Electrode and Peter Yau at the University of Illinois' Mass spectrometric

242 facility for protein identification. We thank Alon Philosof and Connor Skennerton for

243 valuable discussions on bioinformatics analysis. A portion of this research was performed

244 under the Facilities Integrating Collaborations for User Science (FICUS) initiative (award

245503546 to R.H.) and used resources at the DOE Joint Genome Institute and the

246 Environmental Molecular Sciences Laboratory, which are DOE Office of Science User

247 Facilities. Both facilities are sponsored by the Office of Biological and Environmental

248 Research and operated under Contract Nos. DE-AC02-05CH11231 (JGI) and DE-AC05-

249 76RL01830 (EMSL).

\section{References}

253 1. Thamdrup, B. New Pathways and Processes in the Global Nitrogen Cycle. Annu. Rev. $254 \quad$ Ecol. Evol. Syst. 43, 407-428 (2012). 
255 2. Klotz, M. G. \& Stein, L. Y. Nitrifier genomics and evolution of the nitrogen cycle.

256 FEMS Microbiology Letters 278, 146-156 (2008).

257 3. Zumft, W. G. Nitric oxide reductases of prokaryotes with emphasis on the

258 respiratory, heme-copper oxidase type. J. Inorg. Biochem. 99, 194-215 (2005).

259 4. Hemp, J. \& Gennis, R. B. Diversity of the Heme-Copper Superfamily in Archaea:

260 Insights from Genomics and Structural Modeling. Bioenergetics 1-31 (2008).

261 5. Pereira, M. M., Sousa, F. L., Veríssimo, A. F. \& Teixeira, M. Looking for the

262 minimum common denominator in haem-copper oxygen reductases: Towards a

263 unified catalytic mechanism. Biochim. Biophys. Acta BBA - Bioenerg. 1777, 929-934

264 (2008).

265 6. Hemp, J., Christian, C., Barquera, B., Gennis, R. B. \& Martínez, T. J. Helix

266 Switching of a Key Active-Site Residue in the Cytochrome $c b b_{3}$ Oxidases.

267 Biochemistry 44, 10766-10775 (2005).

268 7. Hemp, J. et al. Evolutionary migration of a post-translationally modified active-Site

269 residue in the proton-pumping heme-copper oxygen reductases. Biochemistry $\mathbf{4 5}$,

$270 \quad 15405-15410(2006)$.

271 8. Han, H. et al. Adaptation of aerobic respiration to low $\mathrm{O}_{2}$ environments. Proc. Natl.

$272 \quad$ Acad. Sci. 108, 14109-14114(2011).

273 9. Hemp, J. et al. Comparative Genomics and Site-Directed Mutagenesis Support the

274 Existence of Only One Input Channel for Protons in the C-Family (cbb3 Oxidase) of

275 Heme-Copper Oxygen Reductases. Biochemistry 46, 9963-9972 (2007).

276 10. Chang, H.-Y., Hemp, J., Chen, Y., Fee, J. A. \& Gennis, R. B. The cytochrome $b a_{3}$

277 oxygen reductase from Thermus thermophilus uses a single input channel for proton 
278 delivery to the active site and for proton pumping. Proc. Natl. Acad. Sci. 106, 16169-

$27916173(2009)$.

280 11. Qin, L., Hiser, C., Mulichak, A., Garavito, R. M. \& Ferguson-Miller, S. Identification

281 of conserved lipid/detergent-binding sites in a high-resolution structure of the

282 membrane protein cytochrome c oxidase. Proc. Natl. Acad. Sci. 103, 16117-16122

283 (2006).

284 12. Soulimane, T. et al. Structure and mechanism of the aberrant $b a_{3}$-cytochrome $c$

285 oxidase from Thermus thermophilus. EMBO J. 19, 1766-1776 (2000).

286 13. Tiefenbrunn, T. et al. High resolution structure of the $b a_{3}$ cytochrome $c$ oxidase from

287 Thermus thermophilus in a lipidic environment. PLOS ONE 6, 1-12 (2011).

288 14. Buschmann, S. et al. The Structure of $c b b_{3}$ Cytochrome Oxidase Provides Insights

289 into Proton Pumping. Science 329, 327-330 (2010).

290 15. Hino, T. et al. Structural basis of biological $\mathrm{N}_{2} \mathrm{O}$ generation by bacterial nitric oxide

291 reductase. Science 330, 1666-1670 (2010).

292 16. Gonska, N. et al. Characterization of the quinol-dependent nitric oxide reductase

293 from the pathogen Neisseria meningitidis, an electrogenic enzyme. Sci. Rep. 8, 3637

$294 \quad$ (2018).

295 17. Suharti, Strampraad, M. J., Schröder, I. \& de Vries, S. A novel copper A containing

296 menaquinol NO reductase from Bacillus azotoformans. Biochemistry 40, 2632-2639

$297 \quad(2001)$.

298 18. Al-Attar, S. \& de Vries, S. An electrogenic nitric oxide reductase. FEBS Lett. 589, $299 \quad 2050-2057(2015)$. 
300 19. Strohm, T. O., Griffin, B., Zumft, W. G. \& Schink, B. Growth Yields in Bacterial

301 Denitrification and Nitrate Ammonification. Appl. Environ. Microbiol. 73, 1420-

$3021424(2007)$

303 20. Hanson, B. T. \& Madsen, E. L. In situ expression of nitrite-dependent anaerobic

304 methane oxidation proteins by Candidatus Methylomirabilis oxyfera co-occurring

305 with expressed anammox proteins in a contaminated aquifer. Environ. Microbiol.

$306 \quad$ Rep. 7, 252-264 (2015).

307 21. Jones, A. M., Hollocher, T. C. \& Knowles, R. Nitrous oxide reductase of Flexibacter

308 canadensis: a unique membrane-bound enzyme. FEMS Microbiol. Lett. 92, 205-209

$309 \quad$ (1992).

310 22. Jones, A. M., Adkins, A. M., Knowles, R. \& Rayat, G. R. Identification of a

311 denitrifying gliding bacterium, isolated from soil and able to reduce nitrous oxide in

312 the presence of sulfide and acetylene, as Flexibacter canadensis. Can. J. Microbiol.

313 36, 765-770 (1990).

314 23. Alfredsson, G. A., Kristjansson, J. K., Hjrleifsdottir, S. \& Stetter, K. O.

315 Rhodothermus marinus, gen. nov., sp. nov., a Thermophilic, Halophilic Bacterium

316 from Submarine Hot Springs in Iceland. J. Gen. Microbiol. 299-306 (1988).

317 24. Lübben, M. \& Morand, K. Novel prenylated hemes as cofactors of cytochrome

318 oxidases. Archaea have modified hemes A and O. J. Biol. Chem. 269, 21473-21479

319 (1994).

320 25. Brown, K. R., Allan, B. M., Do, P. \& Hegg, E. L. Identification of Novel Hemes

321 Generated by Heme A Synthase: Evidence for Two Successive Monooxygenase

322 Reactions. Biochemistry 41, 10906-10913 (2002). 
323 26. Fufezan, C., Zhang, J. \& Gunner, M. R. Ligand preference and orientation in $b$ - and

$324 \quad c$-type heme-binding proteins. Proteins Struct. Funct. Bioinforma. 73, 690-704

$325 \quad$ (2008).

326 27. Lin, Y.-W. et al. Introducing a 2-His-1-Glu nonheme iron center into myoglobin

327 confers nitric oxide reductase activity. J. Am. Chem. Soc. 132, 9970-9972 (2010).

328 28. Chen, J. \& Strous, M. Denitrification and aerobic respiration, hybrid electron

329 transport chains and co-evolution. Biochim. Biophys. Acta BBA - Bioenerg. 1827,

$330 \quad 136-144(2013)$.

331 29. Matsumoto, Y. et al. Crystal structure of quinol-dependent nitric oxide reductase

332 from Geobacillus stearothermophilus. Nat. Struct. Mol. Biol. 19, 238-245 (2012).

333 30. Chang, H.-Y. et al. Exploring the proton pump and exit pathway for pumped protons

334 in cytochrome $b a_{3}$ from Thermus thermophilus. Proc. Natl. Acad. Sci. 109, 5259-

$335 \quad 5264(2012)$

336 31. Blomberg, M. R. A. \& Siegbahn, P. E. M. Why is the reduction of NO in cytochrome

$337 c$ dependent nitric oxide reductase (cNOR) not electrogenic? Biochim. Biophys. Acta

338 BBA-Bioenerg. 1827, 826-833 (2013).

339 32. Camejo, P. Y., Oyserman, B. O., McMahon, K. D. \& Noguera, D. R. Integrated Omic

340 Analyses Provide Evidence that a "Candidatus Accumulibacter phosphatis" Strain

341 Performs Denitrification under Microaerobic Conditions. mSystems 4, e00193-18.

342 33. Huang, Y.-M., Straub, D., Blackwell, N., Kappler, A. \& Kleindienst, S. Meta-omics

343 Reveal Gallionellaceae and Rhodanobacter Species as Interdependent Key Players

344 for Fe(II) Oxidation and Nitrate Reduction in the Autotrophic Enrichment Culture

$345 \quad$ KS. Appl. Environ. Microbiol. 87, e00496-21. 

$c b b_{3}$ oxidase: resonance Raman detection of a six-coordinate ferrous heme-nitrosyl species in the binuclear $b_{3} / \mathrm{Cu}_{\mathrm{B}}$ center. Chem. Commun. 51, 17398-17401 (2015).

\section{List of Figures}

351

Figure 1. Comparison of HCO active sites. a) Active-site and proton channel properties of the five characterized HCO families (A-family, B-family, C-family, cNOR, and qNOR). The oxygen reductases all have an active-site composed of high-spin heme, a redox-active cross-linked tyrosine cofactor, and a copper $\left(\mathrm{Cu}_{\mathrm{B}}\right)$ ligated by three histidines. The A-family has two conserved proton channels, whereas the B and Cfamilies only have one. The active-sites of the nitric oxide reductases are composed of a high-spin heme and an iron $\left(\mathrm{Fe}_{\mathrm{B}}\right)$ that is ligated by three histidines and a glutamate. Notably they are missing the tyrosine cofactor. The cNOR and qNOR are also missing conserved proton channels, making them non-electrogenic. b) Sequence alignment of the active-sites of the newly discovered $\mathrm{HCO}$ families that are related to the B-family. c) Predicted active-sites and proton channels for the new HCO families. The eNOR, bNOR, sNOR, and nNOR families contain completely conserved proton channels shown here as arrows. The putative proton channel in the bNOR and eNOR families are highly similar to the K-channel from the B-family oxygen reductase and are colored in red. The Kchannel in the B-family is also similar to the $\mathrm{K}$-channel in the A-family oxygen reductase which is colored in dark red. The proton channel in the C-family is different from these channels and is marked in yellow. The putative proton channels in sNOR and nNOR are marked in cyan and differentiated from the other channels with a dashed black outline. reductases are in shades of blue, whereas nitric oxide reductases are in shades of yellow, green and red.

Figure 3. Biochemical Characterization of the eNOR from Rhodothermus marinus. a) UV-Vis spectrum of isolated eNOR indicates the presence of an unusual heme $a$ signature at $589 \mathrm{~nm}$. b) $\mathrm{NO}$ reductase activity was measured with the use of a Clark electrode in the presence of TMPD and ascorbate as electron donor. c) $\mathrm{N}_{2} \mathrm{O}$ accumulation observed in a culture of Rhodothermus marinus, in the presence of acetylene d) $\mathrm{N}_{2} \mathrm{O}$ production by eNOR from $R$. marinus and qNOR from Persephonella marina.

386

Extended Data Figure 1: Genome of $R$. marinus encodes for the complete denitrification pathway. a. The genes for NapAB, the periplasmic nitrate reductase (Rmar_0413), the nitrite reductases nirK (Rmar_1208) and nirS (Rmar_0652) and nitrous oxide reductase, nosZ (Rmar_2012) are encoded in the $R$. marinus genome. b. The gene neighborhood of eNOR in R. marinus. c. The gene neighborhood of eNOR in Halovivax ruber includes ctaB, an enzyme involved in the biosynthesis of heme $a$. 

denitrification. a. R. marinus converts ${ }^{15} \mathrm{NO}_{3}{ }^{-}$to ${ }^{30} \mathrm{~N}_{2}$. Ratio of ${ }^{30} \mathrm{~N}_{2}$ to ${ }^{28} \mathrm{~N}_{2}$ for each sample. Air is ambient atmosphere as a standard. C0 is a nitrate-free control. 14 0-17 are cultures grown with unlabeled nitrate, transferred to sealed vials after $0-17$ hours, respectively. 15 0-17 are the equivalent samples grown with ${ }^{15} \mathrm{~N}$-labeled nitrate. Error bars represent two standard deviations from three replicate GC/MS measurements. ${ }^{30} \mathrm{~N}_{2}$ enrichments from the ${ }^{15} \mathrm{~N}$-labeled samples are over 30-60x higher than background atmospheric ratios, while unlabeled samples have no significant enrichment over background. b. Growth of $R$. marinus, measured using $\mathrm{OD}_{600 \mathrm{~nm}}$ over 39 hours. $\mathrm{NO}_{3}{ }^{-}$ utilization was established by measuring the concentrations of nitrate in the media using a calorimetric assay. c. R. marinus growth in rich media was compared under denitrifying and non-denitrifying conditions using $\mathrm{OD}_{600 \mathrm{~nm}}$. d. Phenotypic differences of $R$. marinus cultures, under denitrifying and non-denitrifying conditions.

\section{Extended Data Figure 3: Characteristics of eNOR from Rhodothermus marinus a.} SDS-PAGE gel electrophoresis of eNOR shows two bright bands which are estimated to subunits of I and II of the complex. Both subunits appear to run faster than their estimated molecular weight. This is typical for membrane proteins. For comparison, an SDS-PAGE gel of cytochrome $b_{3}$ oxidase from E. coli is included. b. Mass spectrometric identification of eNOR is confirmed by LC/MS/MS analysis. c,d. Absence of $\mathrm{O}_{2}$ reduction by R. marinus eNOR, in comparison to robust $\mathrm{O}_{2}$ reduction by $T$. thermophilus $b a_{3}$-type oxygen reductase. e. UV-visible spectrum of eNOR f. Pyridine hemochrome-spectra of extracted hemes from eNOR showing a peak which is atypical of hemes $a, b$ or $c$.

\section{Extended Data Figure 4: Identification of hemes extracted from eNOR. Comparing} the elution profile of extracted hemes from partially purified $R$. marinus eNOR to bovine cytochrome $c$ oxidase (A-type, $\mathrm{t}=16 \mathrm{~min}$ ), T. thermophilus $b a_{3}$-type oxygen reductase ( $b$ and $A_{s}$-type hemes, $t=12$ min and $t=19$ min) reveals that the heme is most likely an $A_{s}$ type heme. Mass spectra of the peak at $\sim 19$ min from the eNOR hemes elution profile confirms that the heme is an $A_{s}$-type heme with a molecular weight of $920 \mathrm{Da}$.

\section{Extended Data Figure 5: Proton channel in eNOR of Rhodothermus marinus and in} the NOR families bNOR, sNOR and nNOR. a. eNOR contains conserved residues in Helix VII, similar to the location of K-proton channel residues in T. thermophilus $b a_{3^{-}}$ type oxygen reductase. $b$. A multiple sequence alignment of the NOR families eNOR, bNOR, sNOR and nNOR show conserved amino acids in analogous location to the Kchannel in the B-type oxygen reductase. Some conserved residues are also identified in gNOR and may indicate the presence of a conserved proton channel but they do not map to corresponding residues in the B-type oxygen reductase.

\section{Extended Data Figure 6: Conserved amino acids in the eNOR family of enzymes.} Multiple sequence alignment of 23 eNOR sequences from various taxonomically

431 divergent organisms reveals conserved residues that correspond to the active site ligands, proton channel residues and other sequence features that are unique to eNOR. The active 
432 site residues are highlighted in maroon while the proton channel residues are highlighted

433 in blue.

434

435

436

437

438

439

440

\section{List of Tables}

441

442

443

444

445

Table 1. Environmental distribution of the HCO NOR families. Distribution of NOR families in sequenced genomes versus environmental datasets. The newly discovered NOR families account for approximately $2 / 3$ of currently known diversity and $1 / 2$ of the abundance of NORs in nature.

446

Supplementary Table 1. Putative proton channels in the new NOR families - eNOR, bNOR, sNOR, nNOR. A list of conserved residues is noted in the table for each family with a reference sequence according to which the residues are numbered. These conserved residues are compared with amino acids found in analogous positions in the Btype oxygen reductase. distribution of all the NOR families within various bacterial and archaeal phyla within the genomes in release 202 of GTDB was analyzed using HMMs that are specific to each NOR family. the IMG database. A distribution of various NOR families in over 2000 metagenomes on the IMG database was evaluated, and then tabulated according to the environment from which each metagenome is sourced. analysis of denitrification pathways in bacterial genomes and archaeal genomes in release 202 of GTDB was performed by searching for the presence and absence of NarGHI, NapAB, NirK, NirS, NosZ, NosD and the NORs in each genome using curated HMMs for each of the proteins. 
Table 1. Environmental distribution of the HCO NOR families. Distribution of NOR families in sequenced genomes versus environmental datasets. The newly discovered NOR families account for approximately $2 / 3$ of currently known diversity and $1 / 2$ of the abundance of NORs in nature.

\begin{tabular}{|l|r|r|r|}
\hline & NCBI-Genomes & IMG-metagenomes & GTDB-genomes \\
\hline A-family & 20290 & 102368 & 45135 \\
\hline B-family & 1238 & 4683 & 2021 \\
\hline C-family & 13976 & 23015 & 14981 \\
\hline qNOR & 4388 & 7680 & 3458 \\
\hline cNOR & 2801 & 4824 & 2594 \\
\hline eNOR & 68 & 2709 & 547 \\
\hline sNOR & 95 & 872 & 344 \\
\hline bNOR & 51 & 12 & 200 \\
\hline nNOR & 6 & 289 & 32 \\
\hline gNOR & 10 & 913 & 156 \\
\hline NOD & 8 & 539 & 108 \\
\hline N2O & 25 & 597 & .a. \\
\hline
\end{tabular}


Figure 1. Comparison of HCO active sites. a) Active-site and proton channel properties of the five characterized $\mathrm{HCO}$ families (A-family, B-family, C-family, cNOR, and qNOR). The oxygen reductases all have an active-site composed of high-spin heme, a redox-active cross-linked tyrosine cofactor, and a copper $\left(\mathrm{Cu}_{\mathrm{B}}\right)$ ligated by three histidines. The A-family has two conserved proton channels, whereas the $\mathrm{B}$ and $\mathrm{C}$-families only have one. The active-sites of the nitric oxide reductases are composed of a high-spin heme and an iron $\left(\mathrm{Fe}_{\mathrm{B}}\right)$ that is ligated by three histidines and a glutamate. Notably they are missing the tyrosine cofactor. The cNOR and qNOR are also missing conserved proton channels, making them non-electrogenic. b) Sequence alignment of the active-sites of the newly discovered HCO families that are related to the B-family. c) Predicted active-sites and proton channels for the new HCO families. The eNOR, bNOR, sNOR, and nNOR families contain completely conserved proton channels shown here as arrows. The putative proton channel in the bNOR and eNOR families are highly similar to the K-channel from the B-family oxygen reductase and are colored in red. The K-channel in the B-family is also similar to the Kchannel in the A-family oxygen reductase which is colored in dark red. The proton channel in the $\mathrm{C}$-family is different from these channels and is marked in yellow. The putative proton channels in sNOR and nNOR are marked in cyan and differentiated from the other channels with a dashed black outline. 
bioRxiv preprint doi: https://doi.org/10.1101/2021.10.15.464467; this version posted November 10,2021 . The copyright holder for this preprint (which was not certified by peer review) is the author/funder, who has granted bioRxiv a license to display the preprint in perpetuity. It is made available under aCC-BY-NC-ND 4.0 International license.

A
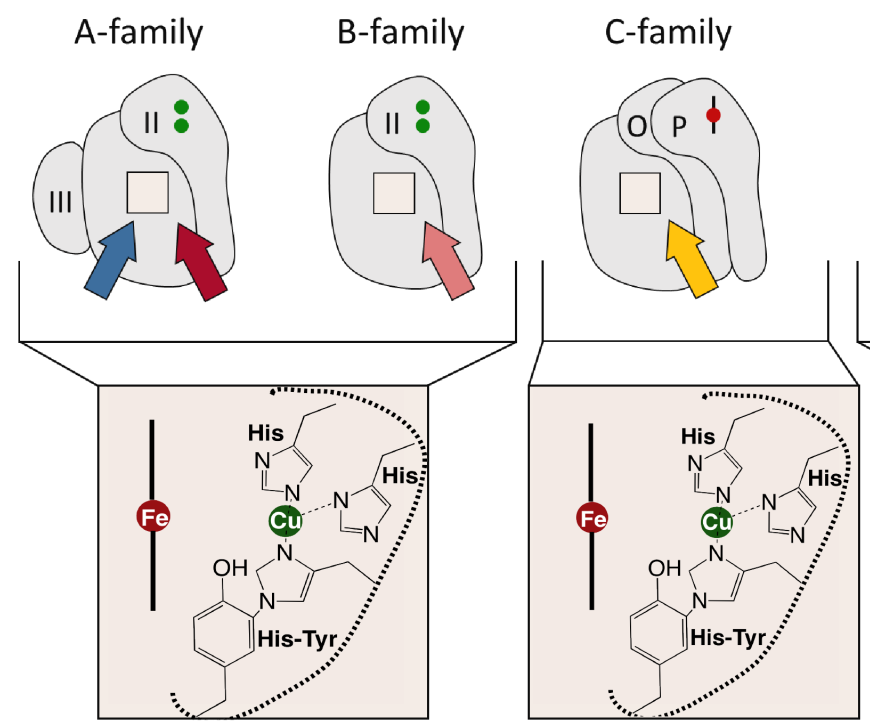

CNOR

qNOR

B

A-family_1M56
B-family_3S8F
ENOR
bNOR
SNOR
gNOR
nNOR
C-family_3MK7
CNOR_3OOR
qNOR_3AYF

PVLYQHILWFFGHPEVYIIVLPAFGIVSHVIATFAK - - GYLPMVYAMVAIGVLGFVVWAHHMYT PLVARTLFWWTGHPIVYFWLLPAYAIIYTILPKQAG - - SDPMARLAFLLFLLLSTPVGFHHQFA AAWYRQMYWI I GHGSQQINLAAMITVWYFLTHVVGG--SEKLSRTAFILYLFFINMGAAHHLLA VMVARTLFWAFGHTAVNIWYLTAVSAWYVIVPKIIG- - SDMLTRVVIIALVIMNITGGFHHQII PLLSKNLIYAFGHIFANSI I YMGVIAVYE IFPKYTG--VYGNFL I AWNASTLFTMI IYPHHL LM ALLYKNVYWWGLDLIADGLVLIYVAGSWYLLAMLLT - - MQHIARAALFVELVVSWFVWSHHLLS PWPFNVAFWLFAHNLMEAMGIMALAAVYALVPLTR - - SPGMGVLAVGLYTLSAIPAFGHHLYT GATDAMVQWWYGHNAVGFFLTAGFLGIMYYFVPKQA - - SYRLSIVHFWALITVYIWAGPHHLHY LTRDKFYWWWVVH LWVEGVWELIMGA I LAFVLVKIT - - IEKWLYVI I AMALISGIIGTGHHYFW QNOR_ 3 AYF

FTMADFWRWWI IHLWVEGIFEVFAVVVIGFLLVQLR - - TVRALYFQFTILLGSGVIGIGHHYYY

C

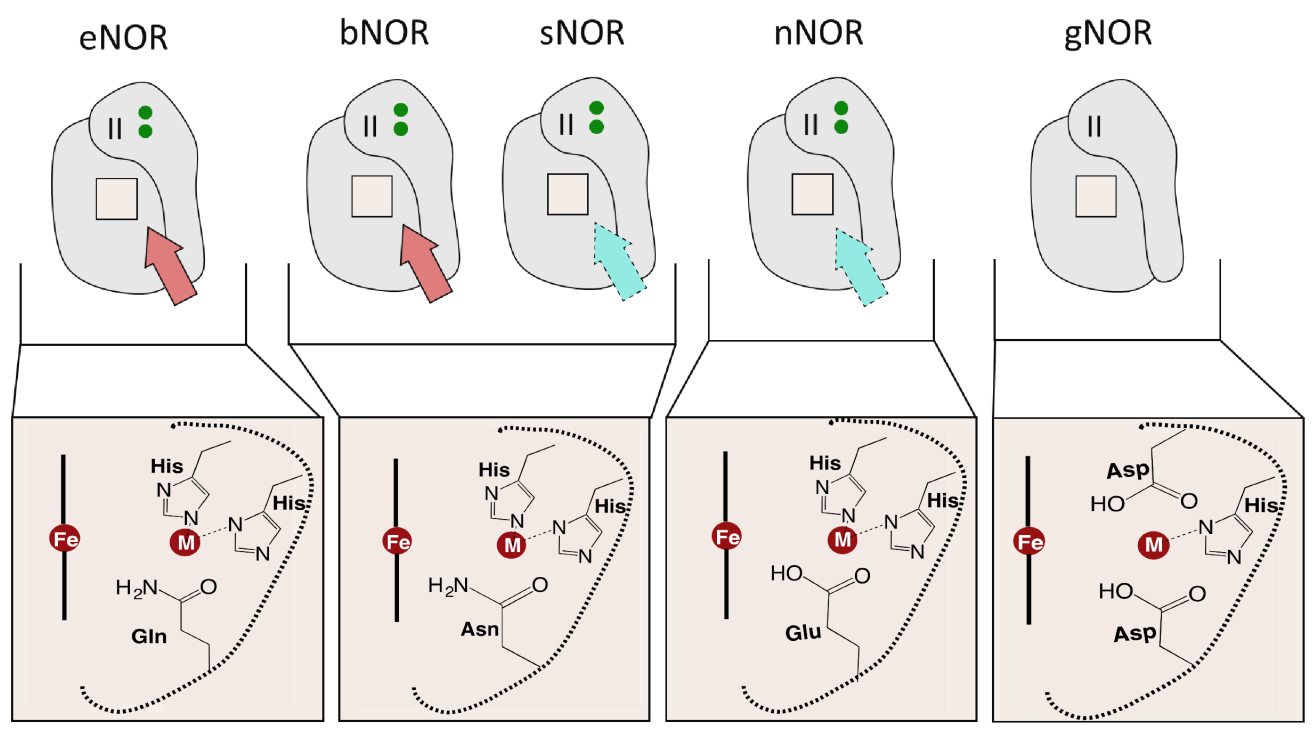


bioRxiv preprint doi: https://doi.org/10.1101/2021.10.15.464467; this version posted November 10,2021 . The copyright holder for this preprint (which was not certified by peer review) is the author/funder, who has granted bioRxiv a license to display the preprint in perpetuity. It is made available under aCC-BY-NC-ND 4.0 International license.

Figure 2. Evolution of nitric oxide reductases. Phylogenetic tree of $\mathrm{HCO}$ families. All of the new NOR families are derived from oxygen reductase ancestors. Oxygen reductases are in shades of blue, whereas nitric oxide reductases are in shades of yellow, green and red. The biochemically characterized eNOR from Rhodothermus marinus is marked with a black star.

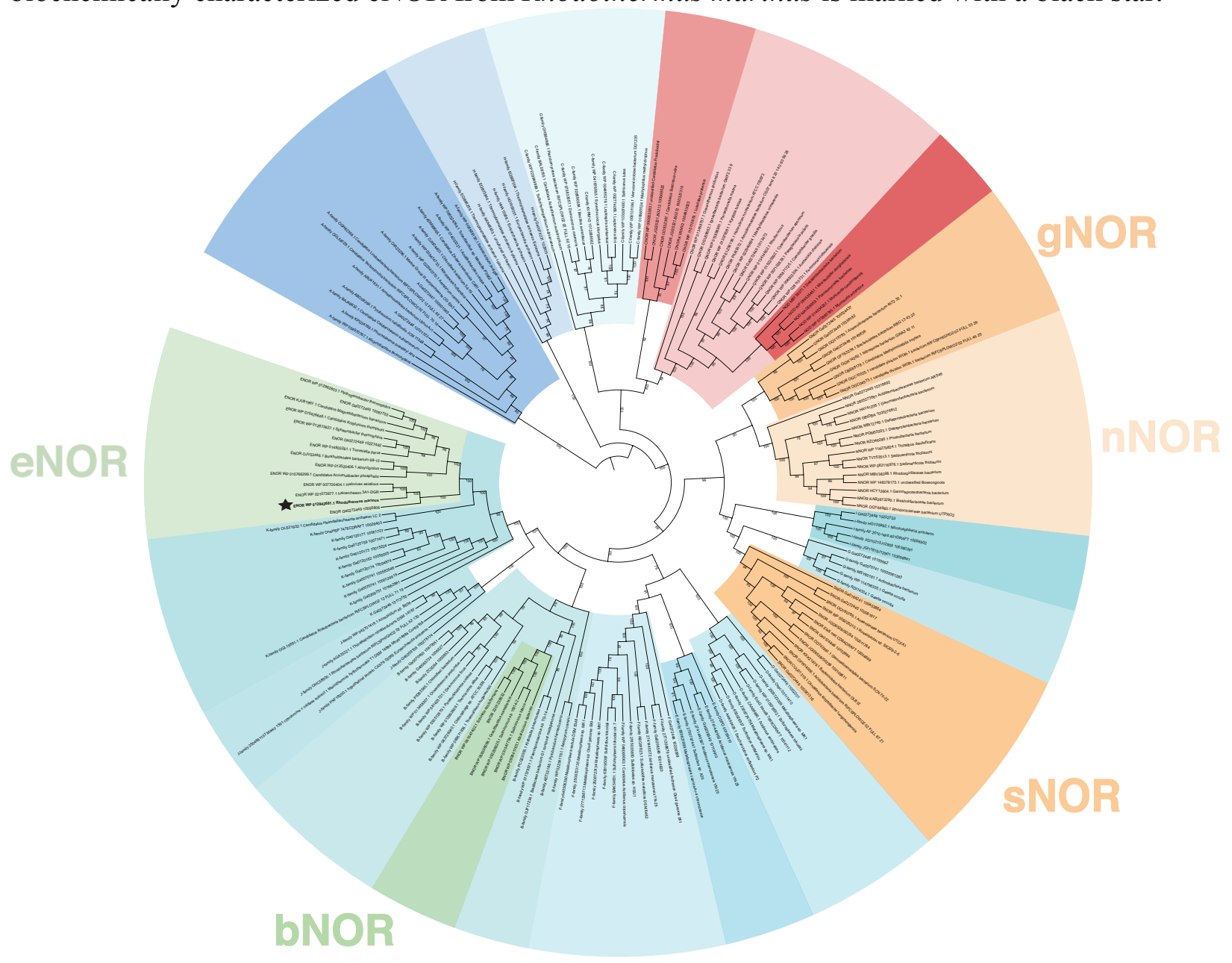


Figure 3. Biochemical Characterization of the eNOR from Rhodothermus marinus. a) UVVis spectrum of isolated eNOR indicates the presence of an unusual heme $a$ signature at $589 \mathrm{~nm}$. b) NO reductase activity was measured with the use of a Clark electrode in the presence of TMPD and ascorbate as electron donor. c) $\mathrm{N}_{2} \mathrm{O}$ accumulation observed in a culture of Rhodothermus marinus, in the presence of acetylene d) $\mathrm{N}_{2} \mathrm{O}$ production by eNOR from $R$. marinus and qNOR from Persephonella marina.

A.

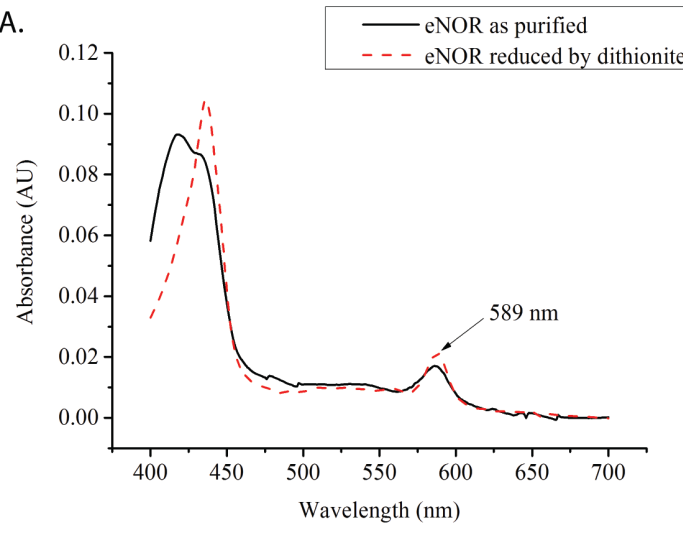

C.

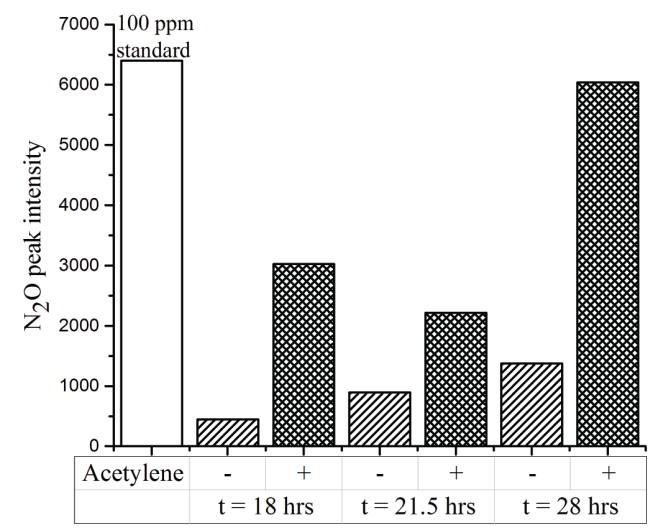

B.

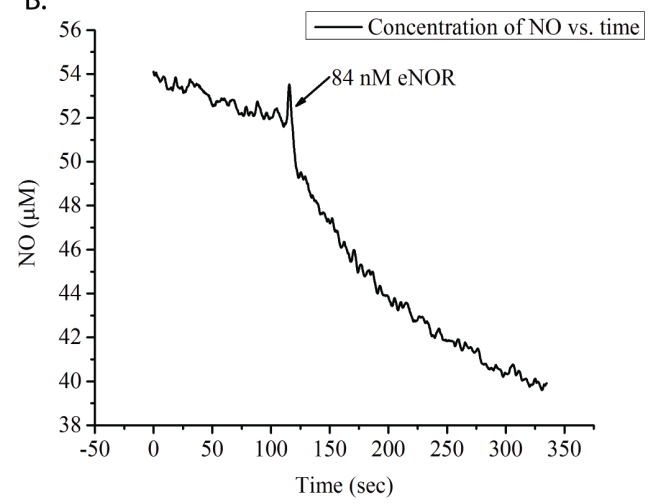

D.

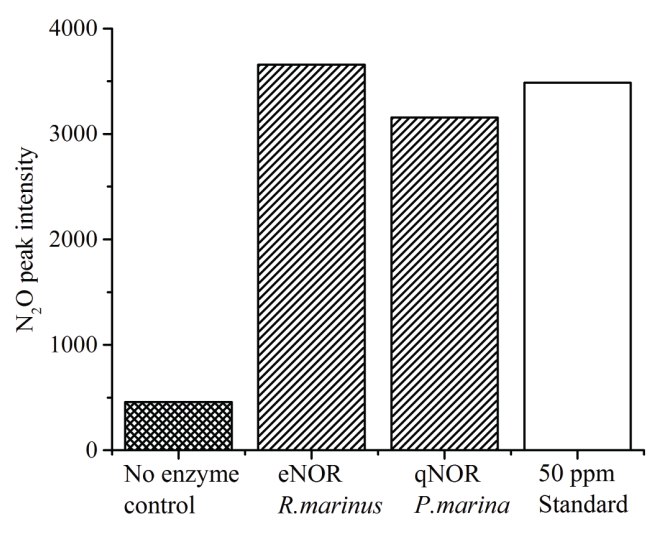


Extended Data Figure 1: Genome of $\boldsymbol{R}$. marinus encodes for the complete denitrification pathway. a. The genes for NapAB, the periplasmic nitrate reductase (Rmar_0413), nitrite reductases nirK (Rmar_1208) and nirS (Rmar_0652), nitric oxide reductase eNOR(Rmar_0161) and nitrous oxide reductase, nosZ (Rmar_2012) are encoded in the $R$. marinus genome. $\mathrm{b}$. The gene neighborhood of eNOR in $R$. marinus. c. The gene neighborhood of eNOR in Magnetospirillum magneticum AMB-1 includes ctaA and ctaB, enzymes involved in the biosynthesis of heme $a$.

a. Denitrification pathway in Rhodothermus marinus

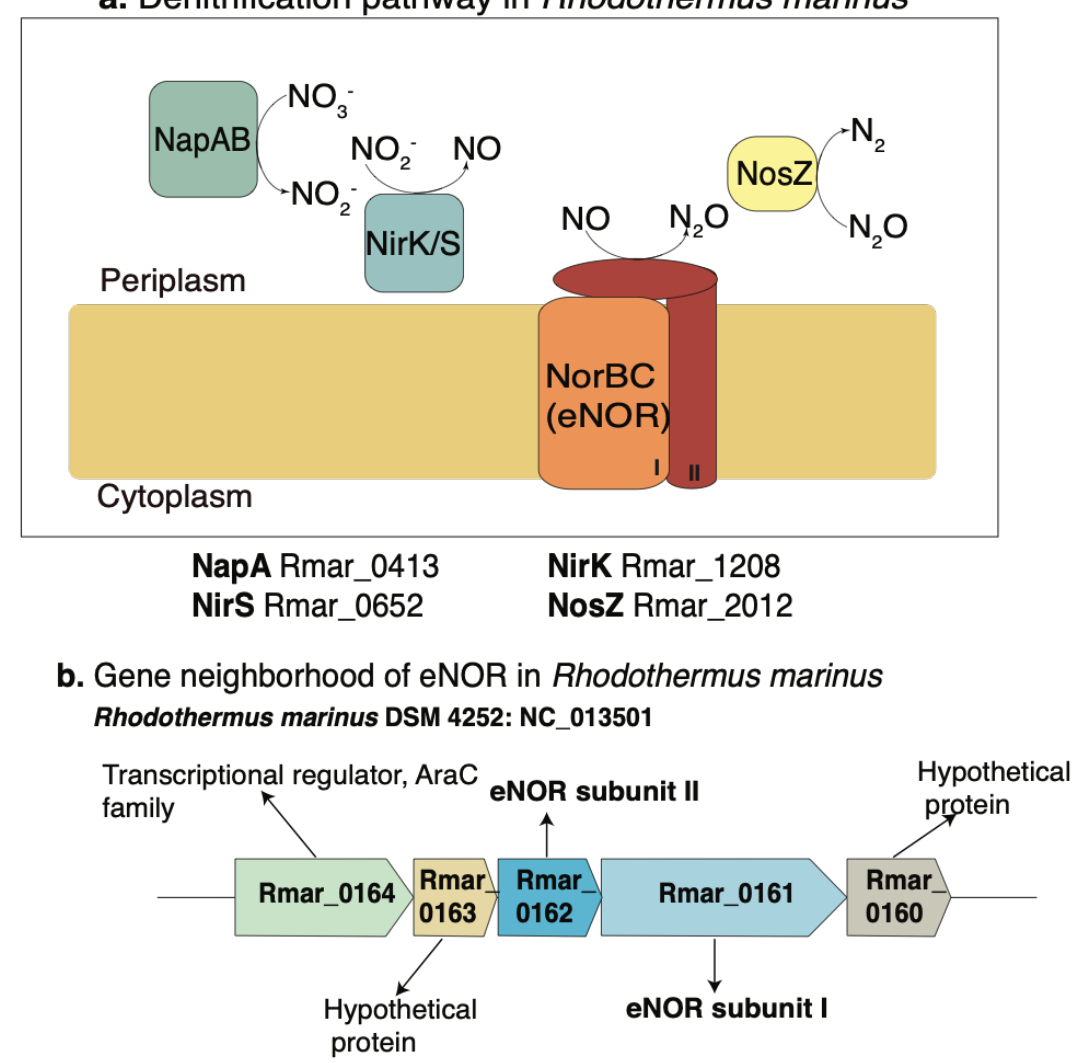

c. Gene neighborhood of eNOR in other organisms include genes for heme a synthesis

Magnetospirillum magneticum AMB-1
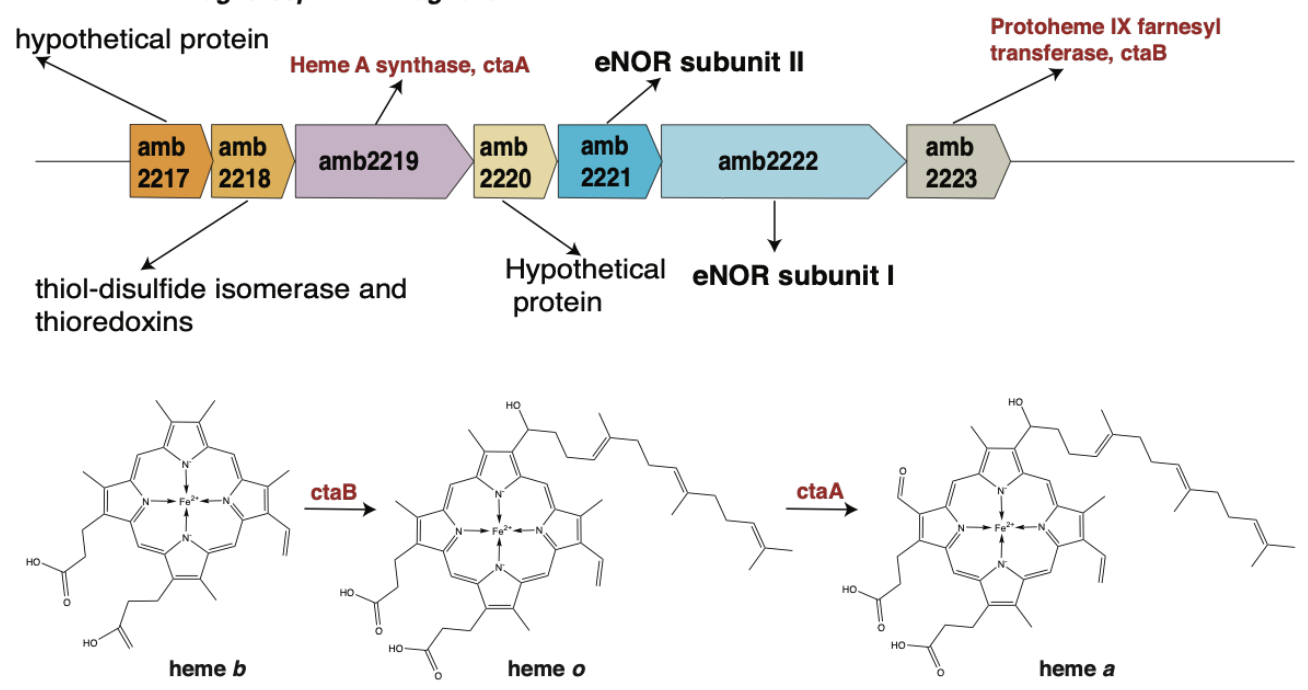
Extended Data Figure 2: Rhodothermus marinus does perform complete denitrification. a. R. marinus converts ${ }^{15} \mathrm{NO}_{3}{ }^{-}$to ${ }^{30} \mathrm{~N}_{2}$. Ratio of ${ }^{30} \mathrm{~N}_{2}$ to ${ }^{28} \mathrm{~N}_{2}$ for each sample. Air is ambient atmosphere as a standard. $\mathrm{C} 0$ is a nitrate-free control. 14 0-17 are cultures grown with unlabeled nitrate, transferred to sealed vials after 0-17 hours, respectively. 15 0-17 are the equivalent samples grown with ${ }^{15} \mathrm{~N}$-labeled nitrate. Error bars represent two standard deviations from three replicate GC/MS measurements. ${ }^{30} \mathrm{~N}_{2}$ enrichments from the ${ }^{15} \mathrm{~N}$-labeled samples are over $30-60 \mathrm{x}$ higher than background atmospheric ratios, while unlabeled samples have no significant enrichment over background. b. Growth of $R$. marinus, measured using $\mathrm{OD}_{600 \mathrm{~nm}}$ over 39 hours. $\mathrm{NO}_{3}{ }^{-}$utilization was established by measuring the concentrations of nitrate in the media using a calorimetric assay. c. $R$. marinus growth in rich media was compared under denitrifying and nondenitrifying conditions using $\mathrm{OD}_{600 \mathrm{~nm}}$. $\mathrm{d}$. Phenotypic differences of $R$. marinus cultures, under denitrifying and non-denitrifying conditions.

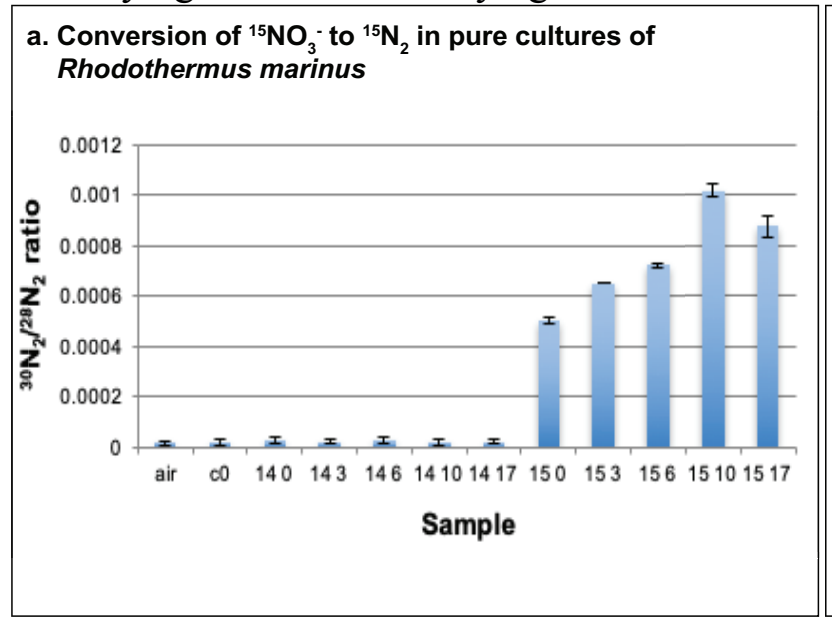

c. Optical density $\left(O D_{600 \mathrm{~nm}}\right)$ of Rhodothermus marinus grown with and without nitrate

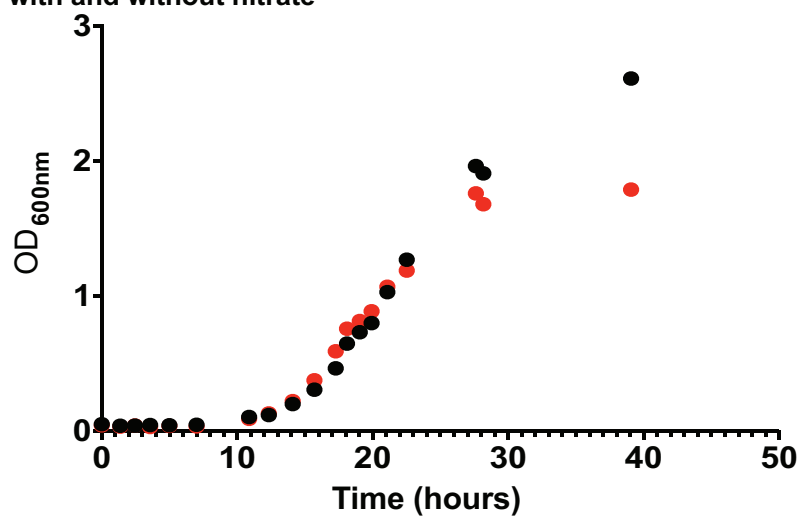

- without nitrate with nitrate

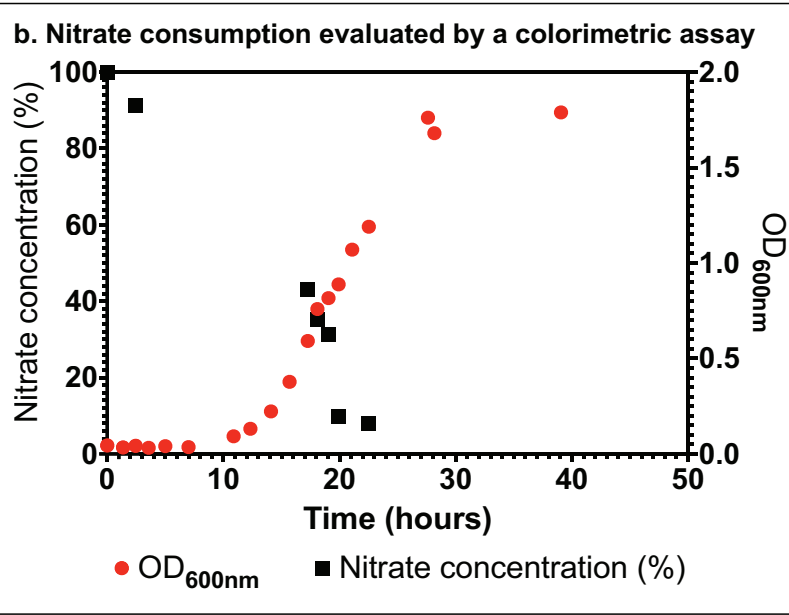

d. Phenotypic differences between cultures of Rhodothermus marinus grown with and without nitrate

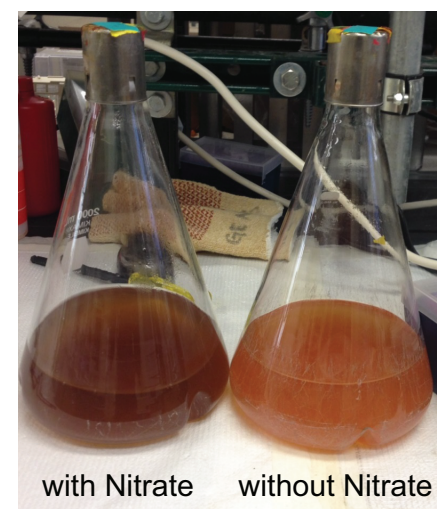


bioRxiv preprint doi: https://doi.org/10.1101/2021.10.15.464467; this version posted November 10,2021 . The copyright holder for this preprint (which was not certified by peer review) is the author/funder, who has granted bioRxiv a license to display the preprint in perpetuity. It is made available under aCC-BY-NC-ND 4.0 International license.

Extended Data Figure 3: Characteristics of eNOR from Rhodothermus marinus a. SDSPAGE gel electrophoresis of eNOR shows two bright bands which are estimated to subunits of I and II of the complex. Both subunits appear to run faster than their estimated molecular weight. This is typical for membrane proteins. For comparison, an SDS-PAGE gel of cytochrome $\mathrm{bo}_{3}$ oxidase from $E$. coli is included. b. Mass spectrometric identification of eNOR is confirmed by LC/MS/MS analysis. c,d. Absence of $\mathrm{O}_{2}$ reduction by $R$. marinus eNOR, in comparison to robust $\mathrm{O}_{2}$ reduction by $T$. thermophilus $b a_{3}$-type oxygen reductase. e. UV-visible spectrum of eNOR $\mathrm{f}$. Pyridine hemochrome-spectra of extracted hemes from eNOR showing a peak which is atypical of hemes $a, b$ or $c$.
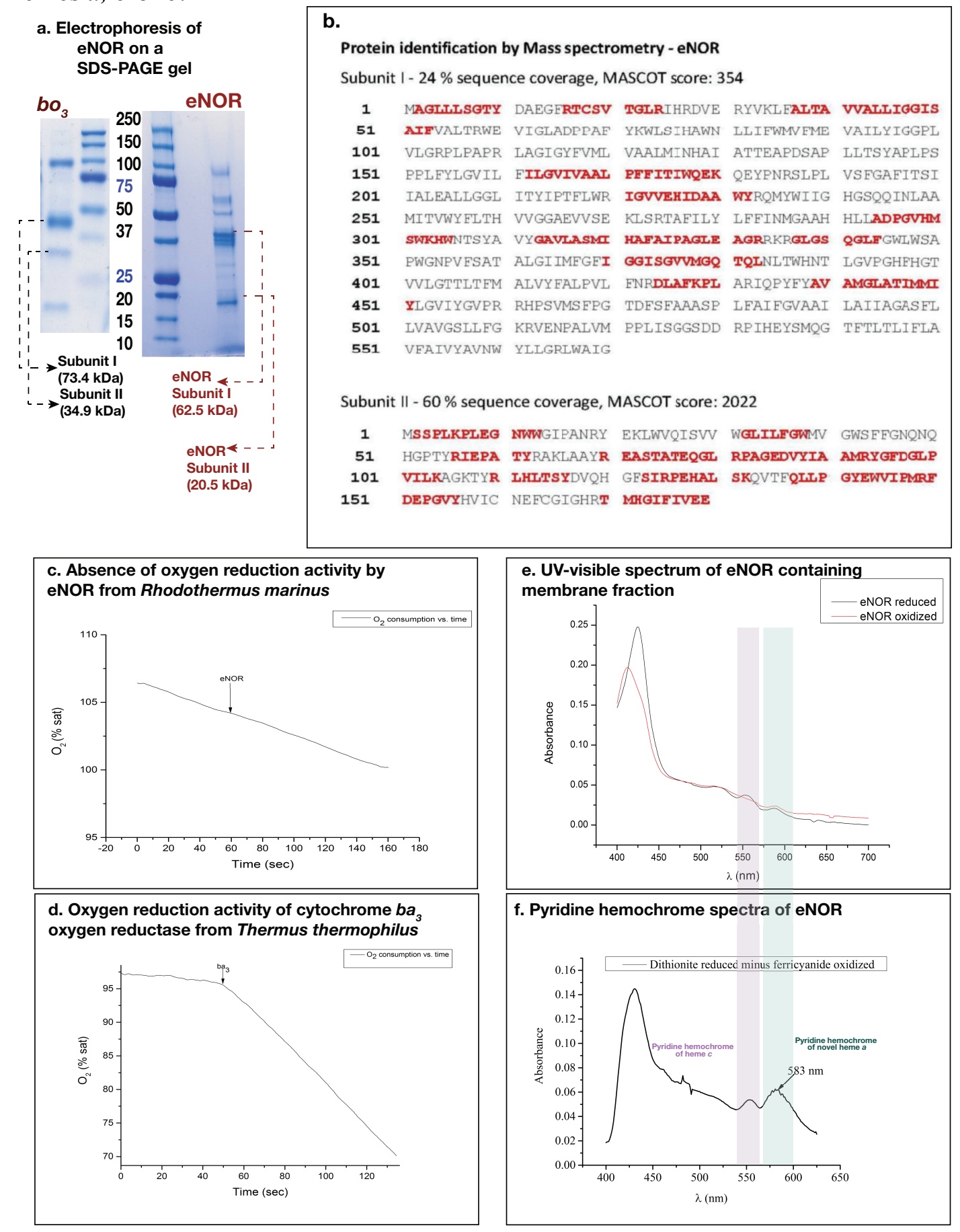
Extended Data Figure 4: Identification of hemes extracted from eNOR. Comparing the elution profile of extracted hemes from partially purified $R$. marinus eNOR to bovine cytochrome $c$ oxidase (A-type, $\mathrm{t}=16 \mathrm{~min}), T$. thermophilus $b a_{3}$-type oxygen reductase $(b$ - and $\mathrm{A}_{\mathrm{s}}$-type hemes, $\mathrm{t}=12 \mathrm{~min}$ and $\mathrm{t}=19 \mathrm{~min}$ ) reveals that the heme is most likely an $\mathrm{A}_{\mathrm{s}}$-type heme. Mass spectra of the peak at $\sim 19$ min from the eNOR hemes elution profile confirms that the heme is an $\mathrm{A}_{\mathrm{s}}$-type heme with a molecular weight of $920 \mathrm{Da}$.

a. Chemical structures of hemes $A$ and heme As.
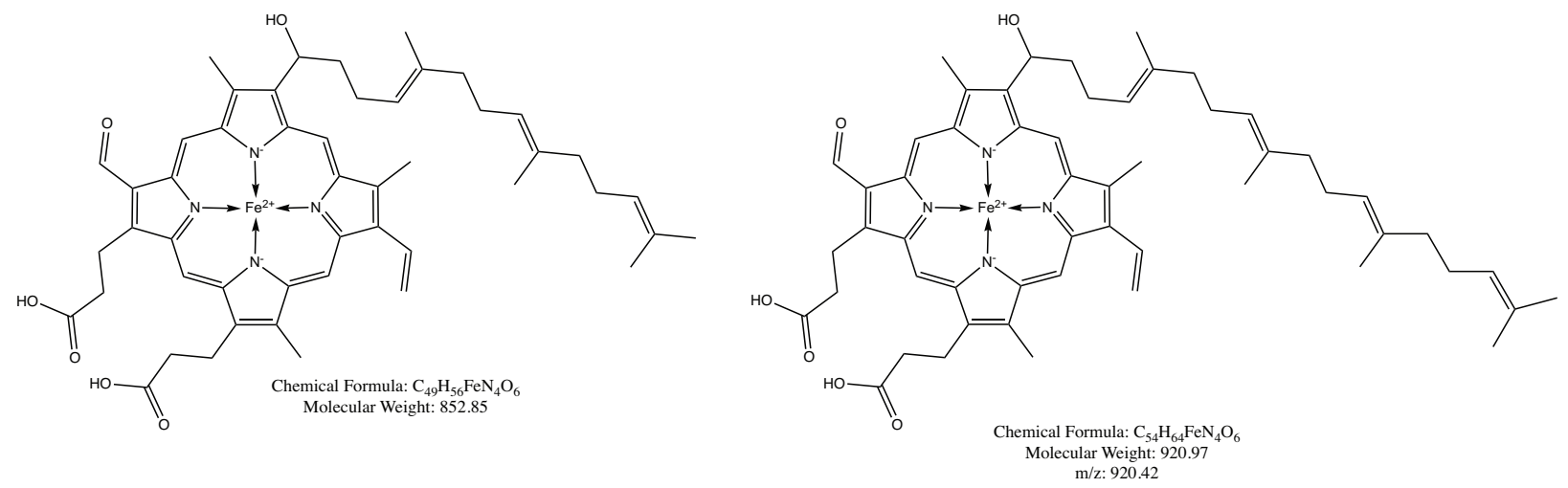

b. Elution profile of hemes extracted from eNOR (LC/MS)
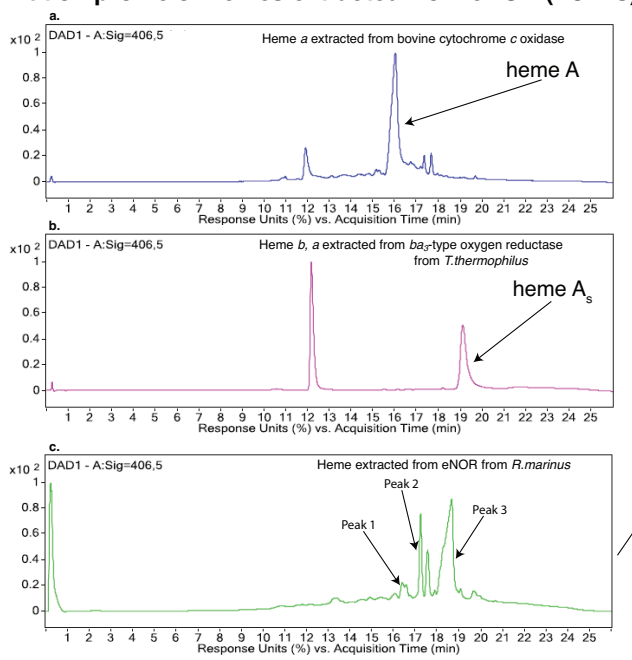

c. Mass spectra corresponding to prominent peaks in the eNOR elution profile

Peak 1
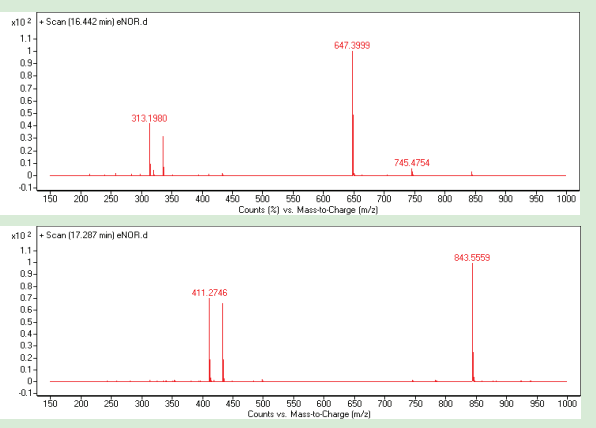

Peak 2

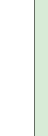

Peak 3

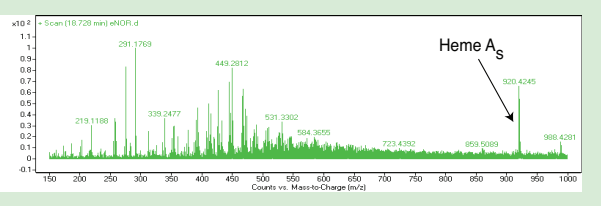


bioRxiv preprint doi: https://doi.org/10.1101/2021.10.15.464467; this version posted November 10,2021 . The copyright holder for this preprint (which was not certified by peer review) is the author/funder, who has granted bioRxiv a license to display the preprint in perpetuity. It is made available under aCC-BY-NC-ND 4.0 International license.

\section{Extended Data Figure 5: Proton channel in eNOR of Rhodothermus marinus and in the NOR families bNOR, sNOR and nNOR. a. eNOR contains conserved residues in Helix VII,} similar to the location of K-proton channel residues in $T$. thermophilus ba-type oxygen reductase. b. A multiple sequence alignment of the NOR families eNOR, bNOR, sNOR and nNOR show conserved amino acids in analogous location to the K-channel in the B-type oxygen reductase. Some conserved residues are also identified in gNOR and may indicate the presence of a conserved proton channel but they do not map to corresponding residues in the B-type oxygen reductase.

a. Comparison of known proton channel from $\boldsymbol{b a}_{3}$ oxygen reductase and putative proton channel in eNOR
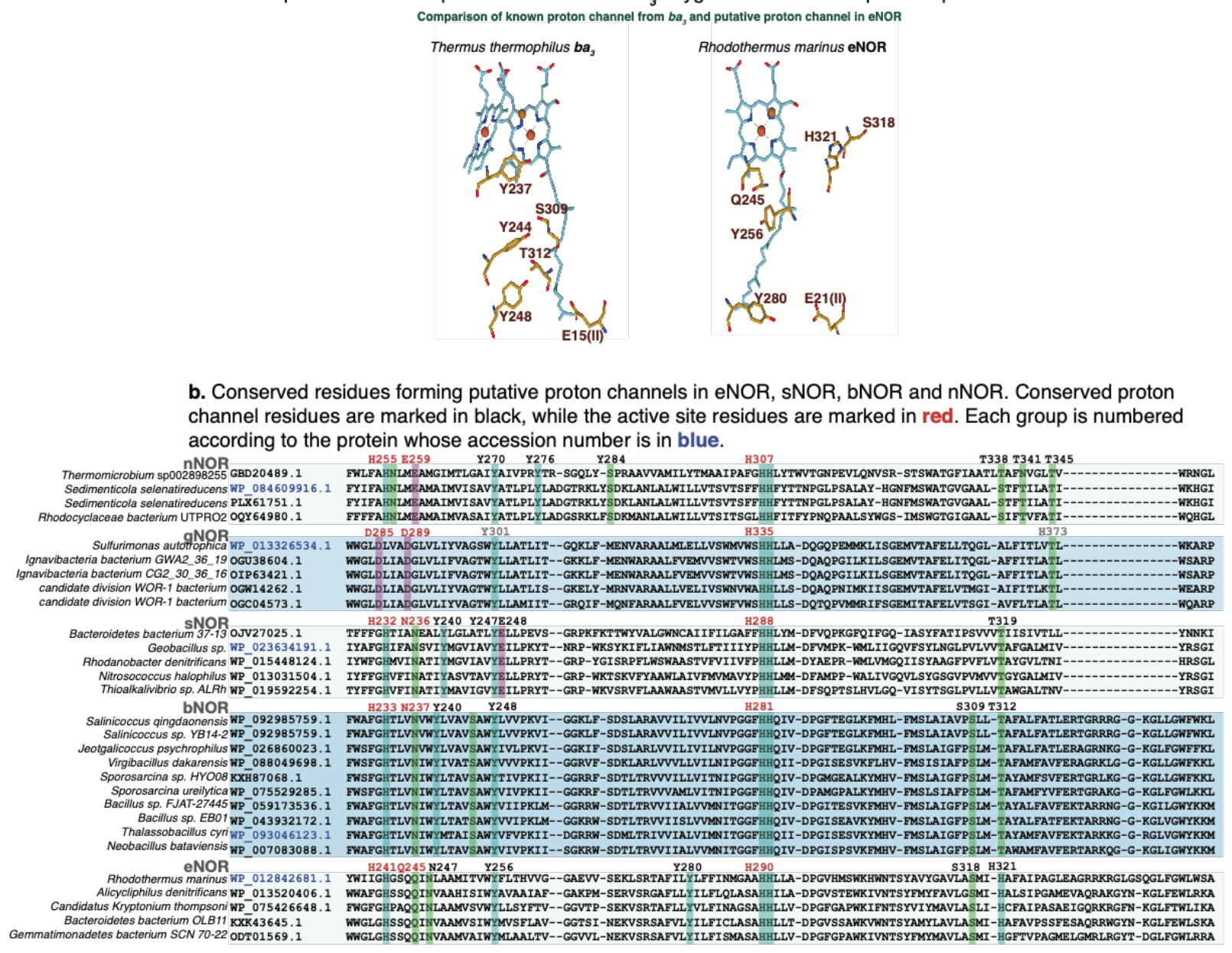
bioRxiv preprint doi: https://doi.org/10.1101/2021.10 15.464467: this version posted November 10,2021 . The copyright holder for this preprint

(which was not certified by peer review) is the author/funder, who has granted bioRxiv a license to display the preprint in perpetuity. It is made available under aCC-BY-NC-ND 4.0 International license.

Extended Data Figure 6: Conserved amino acids in the eNOR family of enzymes. Multiple sequence alignment of 23 eNOR sequences from various taxonomically divergent organisms reveals conserved residues that correspond to the active site ligands, proton channel residues and other sequence features that are unique to eNOR. The active site residues are highlighted in maroon while the proton channel residues are highlighted in blue. 
bioRxiv preprint doi: https://doi.org/10.1101/2021.10.15.464467; this version posted November 10, 2021. The copyright holder for this preprint (which was not certified by peer review) is the author/funder, who has granted bioRxiv a license to display the preprint in perpetuity. It is made available under aCC-BY-NC-ND 4.0 International license.

a. Sequence alignment of eNOR - Subunit I showing conserved amino acid residues according to R.marinus eNOR numbering

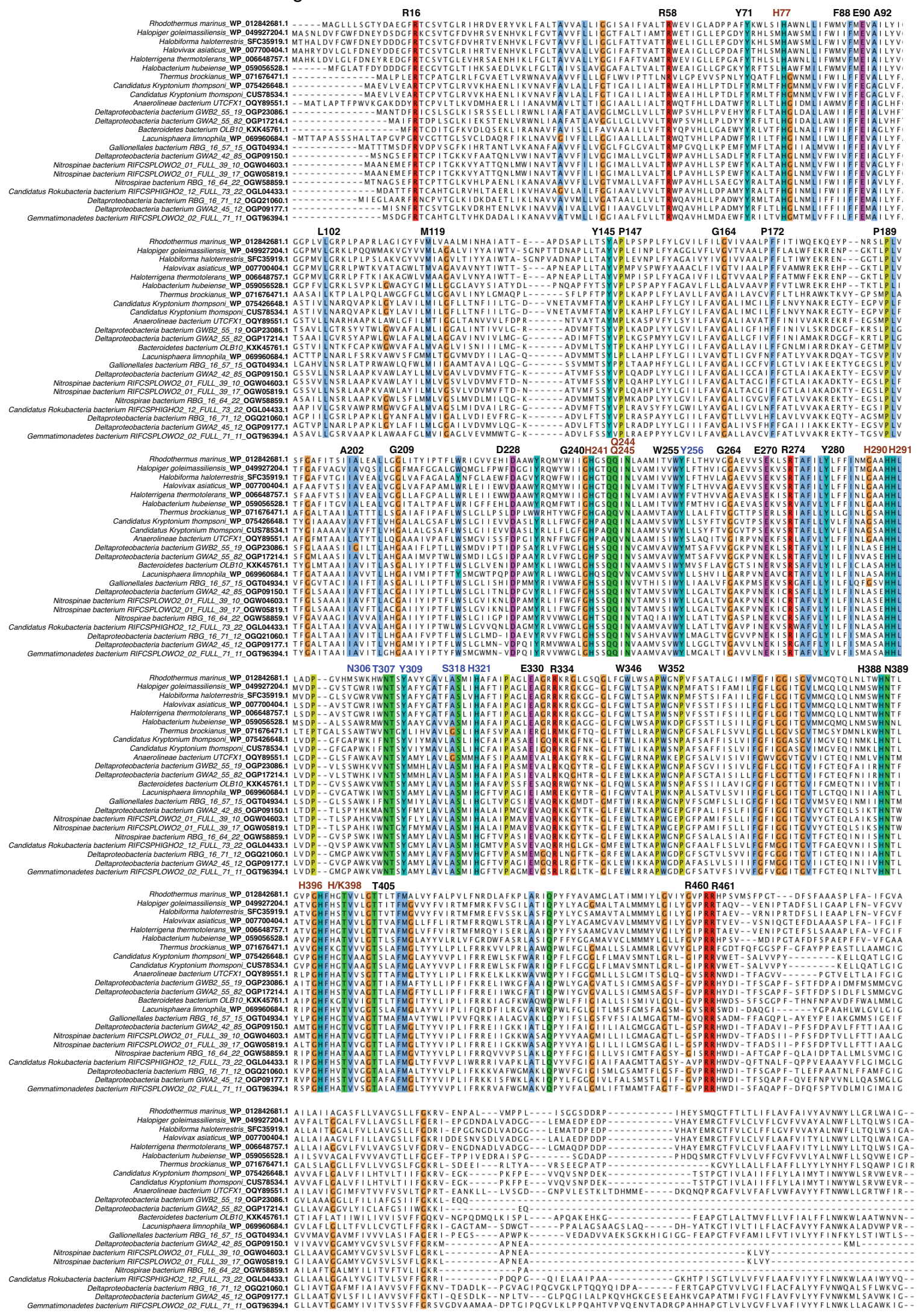




\section{Materials and Methods}

\section{Growth and Expression Conditions}

Rhodothermus marinus DSM 4252 was inoculated from frozen stock and grown in $5 \mathrm{ml}$ of DSM Medium 630 with $10 \mathrm{~g} / \mathrm{L} \mathrm{NaCl}$ at $60^{\circ} \mathrm{C}$ for $36 \mathrm{hrs}$. It was then inoculated into a larger secondary culture and grown overnight. $25 \mathrm{ml}$ of the culture was inoculated into $1 \mathrm{~L}$ of medium with $30 \mathrm{mM}$ nitrate added. The cells were shaken at $75 \mathrm{rpm}$ and grown at $60{ }^{\circ} \mathrm{C}$. The cells were pelleted by centrifugation at $8000 \mathrm{rpm}$. The cell pellet was either directly used for protein purification or frozen at $-80{ }^{\circ} \mathrm{C}$ until the time of use.

\section{Labeled ${ }^{15}$ NO experiments}

We used labeled nitrate $\left({ }^{15} \mathrm{NO}_{3}{ }^{2-}\right)$ to verify that Rhodothermus marinus DSM 4252 was capable of complete denitrification $\left(\mathrm{NO}_{3}{ }^{-}\right.$to $\left.\mathrm{N}_{2}\right)$ using eNOR as the sole nitric oxide reductase. Cultures were inoculated into flasks containing media with either ${ }^{14} \mathrm{NO}_{3}{ }^{2-},{ }^{15} \mathrm{NO}_{3}{ }^{2-}$, or no nitrate. The cultures were then allowed to grow microaerobically for a period of time before being subsampled for transfer to sealed vials in order to allow accumulation of gaseous end products. Samples were taken from each media composition after $0,3,6,10$, and 17 hours. The headspace was sampled after 20 hours of growth in sealed vials via gastight GC syringe and immediately injected into a Hewlett Packard 5972 gas chromatograph/mass spectrometer. Chromatogram peaks corresponding to isotopologues of $\mathrm{NO}, \mathrm{N}_{2} \mathrm{O}$, and $\mathrm{N}_{2}$ were identified by their mass spectra and peak areas were quantified relative to ambient air. As ${ }^{15} \mathrm{~N}$ cultures were grown in isotopically pure ${ }^{15} \mathrm{NO}_{3}{ }^{2-}$, complete denitrification should result in accumulation of ${ }^{30} \mathrm{~N}_{2}$ at a 1:2 ratio relative to nitrate consumption. ${ }^{30} \mathrm{~N}_{2}$ should only accumulate if eNOR is functioning as part of a complete denitrification pathway. If eNOR does not function effectively as a nitric oxide reductase, then

${ }^{15} \mathrm{NO}$ should be seen to accumulate. Instead, only the ${ }^{30} \mathrm{~N}_{2}$ peak was observed, indicating the eNOR 
functioned effectively as a nitric oxide reductase for denitrification. Over the course of incubations,

${ }^{30} \mathrm{~N}_{2}$ was seen to accumulate to more than $50 \mathrm{x}$ background. ${ }^{14} \mathrm{~N}$ samples showed no significant

accumulation of ${ }^{30} \mathrm{~N}_{2}$ above background, confirming that the ${ }^{30} \mathrm{~N}_{2}$ in ${ }^{15} \mathrm{~N}$ samples was due to denitrification of labeled nitrate. NO was not seen to accumulate in any of the cultures. These results demonstrate that eNOR is a functional nitric oxide reductase and can be used as part of a complete denitrification pathway.

\section{Purification of eNOR}

The culture of Rhodothermus marinus, once harvested, was re-suspended in $100 \mathrm{mM}$ Tris- $\mathrm{HCl}$, pH 8 with $10 \mathrm{mM} \mathrm{MgCl}_{2}$ and $50 \mu \mathrm{g} / \mathrm{ml}$ DNase, using a Bamix homogenizer. The resulting solution was spun down at $42000 \mathrm{rpm}$ in a Beckman Ultracentrifuge. The membrane pellet was collected and re-suspended in $20 \mathrm{mM}$ Tris- $\mathrm{HCl}, \mathrm{pH} 7.5,1 \%$ CHAPS (Affymetrix) to a final concentration of $40-50 \mathrm{mg} / \mathrm{ml}$. The solution was stirred at $4{ }^{\circ} \mathrm{C}$ for $1 \mathrm{hr}$. In this step a lot of peripheral membrane proteins appear to be solubilized and the remaining protein is pelleted by spinning down at 42000 rpm for $1 \mathrm{hr}$. The remaining pellet is then solubilized in $20 \mathrm{mM}$ Tris-HCl, $\mathrm{pH} 7.5,1 \% \mathrm{DDM}$ (Affymetrix) at a final protein concentration of around 5-10 $\mathrm{mg} / \mathrm{ml}$. The DDM solubilized fraction was once again centrifuged at $42000 \mathrm{rpm}$ to pellet down protein that was not solubilized.

The solubilized protein was then loaded on a DEAE CL-6B (Sigma) column, pre-equilibrated in $20 \mathrm{mM}$ Tris-HCl, $\mathrm{pH} 7.5,0.05 \%$ DDM, and subjected to a linear gradient spanning from 0 to 500 $\mathrm{mM} \mathrm{NaCl}$. The fraction containing the eNOR, identified using a peak at $591 \mathrm{~nm}$, corresponding to the peak of cytochrome 'a1' in Magnetospirillum magnetotacticum', eluted at around $200 \mathrm{mM}$ salt. This fraction was then loaded on a Q Sepharose High Performance (GE Healthcare) column, pre-equilibrated with $20 \mathrm{mM}$ Tris-HCl, $\mathrm{pH}$ 7,5, $0.05 \% \mathrm{DDM}$ and then eluted in a gradient from 0 to $1 \mathrm{M} \mathrm{NaCl}$. The eNOR containing fraction was eluted at around $250 \mathrm{mM}$ salt and the eluted 
fraction was then loaded on a Chelating Sepharose (GE Healthcare) column, loaded with $\mathrm{Cu}^{2+}$ and equilibriated with $20 \mathrm{mM}$ Tris- $\mathrm{HCl}, 500 \mathrm{mM} \mathrm{NaCl}$, as previously described for cytochrome $\mathrm{caa}_{3}$ from Rhodothermus marinus ${ }^{2}$. The eNOR fraction was once again loaded on a Q Sepharose High performance column, and a gradient was run between 0 and $300 \mathrm{mM} \mathrm{NaCl}$ at low flow rates $(0.5$ $\mathrm{ml} / \mathrm{min}$ ) and the first peak was found to be the eNOR.

\section{Gel Electrophoresis}

The purified eNOR was run on a Tris-Hepes 4-20\% acrylamide gel (NuSep) in the recommended Tris-Hepes-SDS running buffer at $120 \mathrm{~V}$ for $\sim 1 \mathrm{hr}$. The protein was visualized and compared to the Precision Plus Protein ${ }^{\mathrm{TM}}$ Dual Color Standards (BIO-RAD).

\section{UV-Visible Spectroscopy}

All spectra were recorded on a HP Agilent 8453 UV-Vis spectrophotometer using a quartz cuvette from Starna Cells (No. 16.4-Q-10/Z15). Potassium Ferricyanide was used to obtain the oxidized spectrum, and dithionite was used to obtain the reduced spectrum.

\section{Pyridine Hemochrome Assay}

The hemes in eNOR were analyzed using a pyridine hemochrome assay ${ }^{3}$. A stock solution of 200 $\mathrm{mM} \mathrm{NaOH}$ with $40 \%$ pyridine was prepared. The stock solution was mixed 1:1 with the protein and an oxidized spectrum was obtained by adding $3 \mu \mathrm{l}$ of $100 \mathrm{mM} \mathrm{K}_{3} \mathrm{Fe}(\mathrm{CN})_{6}$. A reduced spectrum was similarly prepared by adding a few crystals of sodium dithionite. The reduced minus oxidized spectrum was used to identify the heme co-factors 


\section{Heme extraction and HPLC Analysis}

The hemes from eNOR were extracted and analyzed using an HPLC elution profile according to established protocols $^{4,5} .50 \mu \mathrm{l}$ of eNOR was mixed with $0.45 \mathrm{ml}$ of acetone / $\mathrm{HCl}(19: 1)$ and incubated for 20 minutes at room temperature after shaking. The mixture was centrifuged at 14,000 rpm for 2 minutes, followed by addition of $1 \mathrm{ml}$ of ice cold water, and $0.3 \mathrm{ml}$ of $100 \%$ ethyl acetate to the supernatant. The water/ethyl acetate mixture was vortexed and centrifuged again for 2 minutes. The ethyl acetate phase was recovered and concentrated using a speed vac.

The extracted hemes were analyzed using an Agilent 1290 Infinity LC attached to an Agilent 6230 TOF LC/MS equipment by separation using an Agilent Eclipse Plus C18 column (2.1x300 mm, $1.8 \mu \mathrm{m}, 600 \mathrm{bar})$ and an acetonitrile (0.05\%TFA) / water (0.05\% TFA) gradient from 20 to $95 \%$.

\section{NO reductase activity verification using GC}

Anaerobic reaction conditions were set up in a $5 \mathrm{~mL}$ clear serum vial (Voigt Global Distribution, Inc) sealed with a $20 \mathrm{~mm}$ rubber stopper, by passing $\mathrm{N}_{2}$ through $2 \mathrm{ml}$ of $20 \mathrm{mM} \mathrm{KPi}, 0.05 \%$ DDM, pH 7.5 with $1 \mathrm{mM}$ TMPD, 5 mM Ascorbate. A control was performed by adding only $50 \mu \mathrm{M}$ NO. Sample reactions were begun by adding eNOR to a final concentration of $100 \mathrm{nM}$. The reaction was incubated at $42{ }^{\circ} \mathrm{C}$ for half an hour before the headspace was injected into an HP Agilent 5890 Series GC, fitted with a TCD and ECD (SRI Instruments) for verification of $\mathrm{N}_{2} \mathrm{O}$ production.

\section{Turnover measurement using a Clark electrode}

A sealed chamber fitted with an ISO-NO (World Precision Instruments) electrode was used for NO reductase activity measurements. $1 \mathrm{mM}$ TMPD or $100 \mu \mathrm{M}$ PMS and $4 \mathrm{mM}$ Ascorbate were

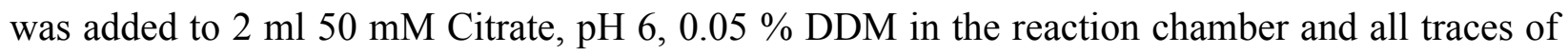
oxygen were removed by passing water-saturated Argon for 20 minutes through the solution. This 
is similar to the protocol described for cNOR from Thermus thermophilus ${ }^{6}$. The buffer system also contained an oxygen scavenging system constituting $100 \mathrm{nM}$ catalase, $35 \mathrm{nM}$ Glucose oxidase and $90 \mathrm{nM}$ Glucose. The NO reduction traces were recorded using a Duo-18 (World Precision Instruments), and activities calculated from the slope of the traces.

\section{LC/MS/MS analysis}

Mass spectrometric analysis was conducted at the Protein Sciences Facility, Roy J Carver Biotechnology Center, University of Illinois, Urbana, IL 61801 using a Thermo LTQ Velos ETD pro mass spectrometer. For liquid samples, the samples were cleaned up using G-Biosciences Perfect Focus (St. Louis MO) prior to digestion with trypsin. Digestion was done using proteomics grade trypsin 1:20 (G-Biosciences, St. Louis, MO) and a CEM Discover Microwave Reactor (Mathews, NC) for 15 minutes at $55^{\circ} \mathrm{C}$ at 50 Watts. Digested peptides were extracted $3 \mathrm{X}$ using $50 \%$ acetonitrile containing 5\% formic acid, pooled and dried using a Speedvac (Thermo Scientific). The dried peptides were suspended in 5\% acetonitrile containing $0.1 \%$ formic acid and applied to LC/MS.

HPLC for the trypsin digested peptides was performed with a Thermo Fisher Dionex 3000 RSLCnano using Thermo Acclaim PepMap RSLC column (75 $\mu \mathrm{m}$ x 15 cm C-18, $2 \mu \mathrm{m}, 100 \AA)$ and a Thermo Acclaim PepMap 100 Guard column (100 $\mu \mathrm{m}$ x 2 cm, C-18, $5 \mu \mathrm{m}, 100 \AA)$, solvents were water containing $0.1 \%$ formic acid (A) and acetonitrile containing $0.1 \%$ formic acid (B) at a flow rate of 300 nanoliters per minute at $40^{\circ} \mathrm{C}$. Gradient was from $100 \%$ A to $60 \% \mathrm{~B}$ in 60 minutes. The effluent from the UHPLC was infused directly into a Thermo LTQ Velos ETD Pro mass spectrometer. 
Control and data acquisition of the mass spectrometer was done using Xcalibur 2.2 under data dependent acquisition mode, after an initial full scan, the top five most intense ions were subjected to MS/MS fragmentation by collision induced dissociation. The raw data were processed by Mascot Distiller (Matrix Sciences, London, UK) and then by Mascot version 2.4. The result was searched against NCBI NR Protein database.

\section{Analysis of heme-copper oxygen reductase phylogeny and distribution in environmental datasets}

We performed a large-scale analysis of heme-copper oxygen reductase $(\mathrm{HCO})$ protein sequences in the NCBI and IMG databases with BLASTP using an e-value of $1 \mathrm{e}^{-}{ }^{3}$ to generate a database of HCO sequences that had at least some of the conserved amino acids previously identified in subunit $\mathrm{I}^{7}$. We then used the database of HCOs, filtered it with a sequence cut-off of $50 \%$ to generate the multiple sequence alignment, MSA1. A phylogenetic tree (Figure 2) was inferred using IQ-TREE $2^{8}$ with the Dayhoff substitution matrix, Gamma model of rate heterogeneity and 1000 ultrafast bootstraps. Using the curated HMMs for each of the HCO family oxygen reductases ${ }^{9}$, we probed release 202 of the Genome Taxonomy Database ${ }^{10}$ for distribution of the NOR families - eNOR, bNOR, sNOR, nNOR, gNOR, cNOR and qNOR - in bacteria and archaea. Curated HMMs for the nitrate reductases (NapAB, NarGH), nitrite reductases (NirK, NirS) and nitrous oxide reductases (NosD and NosZ) were sourced from the HMMs database of MagicLamp ${ }^{11}$. 
Analysis of $\mathrm{HCO}$ distribution in various ecosystems were performed using the metagenomes in

the IMG database. Approximately 2300 metagenomes were identified which were sourced from 44 environments identified by IMG. The number of different HCOs in each of these environments were extracted using BLASTP and query sequences that belong to each of the different HCO families.

\section{References}

1. Tamegai, H., Yamanaka, T. \& Fukumori, Y. Purification and properties of a 'cytochrome al'-like hemoprotein from a magnetotactic bacterium, Aquaspirillum magnetotacticum. Biochim. Biophys. Acta BBA - Gen. Subj. 1158, 237-243 (1993).

2. Pereira, M. M. et al. The caa3 terminal oxidase of the thermohalophilic bacterium Rhodothermus marinus: a HiPIP:oxygen oxidoreductase lacking the key glutamate of the Dchannel. Biochim. Biophys. Acta BBA - Bioenerg. 1413, 1-13 (1999).

3. Berry, E. A. \& Trumpower, B. L. Simultaneous determination of hemes a, b, and c from pyridine hemochrome spectra. Anal. Biochem. 161, 1-15 (1987).

4. Sone, N. \& Fujiwara, Y. Haem O can replace haem A in the active site of cytochrome c oxidase from thermophilic bacterium PS3. FEBS Lett. 288, 154-158 (1991).

5. Reinhold-Hurek, B. \& Zhulin, I. B. Terminal oxidases of Azoarcus sp. BH72, a strictly respiratory diazotroph. FEBS Lett. 404, 143-147 (1997).

6. Schurig-Briccio, L. A. et al. Characterization of the nitric oxide reductase from Thermus thermophilus. Proc. Natl. Acad. Sci. U. S. A. 110, 12613-12618 (2013).

7. Hemp, J. \& Gennis, R. B. Diversity of the Heme-Copper Superfamily in Archaea: Insights from Genomics and Structural Modeling. Bioenergetics 1-31 (2008). 
8. Minh, B. Q. et al. IQ-TREE 2: New Models and Efficient Methods for Phylogenetic Inference in the Genomic Era. Mol. Biol. Evol. 37, 1530-1534 (2020).

9. Murali, R., Hemp, J., Orphan, V. \& Bisk, Y. FIND: Identifying Functionally and Structurally Important Features in Protein Sequences with Deep Neural Networks. bioRxiv 592808 (2019) doi:10.1101/592808.

10. Parks, D. H. et al. A standardized bacterial taxonomy based on genome phylogeny substantially revises the tree of life. Nat. Biotechnol. 36, 996-1004 (2018).

11. Garber, A. MagicLamp: toolkit for annotation of 'omics datasets using curated HMM sets. (2020). 